\title{
INDICADOR DE EDUCAÇÃO FINANCEIRA: PROPOSIÇÃO DE UM INSTRUMENTO A PARTIR DA TEORIA DA RESPOSTA AO ITEM*
}

\author{
Kelmara Mendes Vieira ${ }^{1}$ (1) \\ Fernando de Jesus Moreira Junior ${ }^{1}$ ( \\ Ani Caroline Grigion Potrich ${ }^{1} \bullet$
}

\begin{abstract}
RESUMO: Este trabalho teve por objetivo construir e validar um indicador de educação financeira, assunto relevante que está entre os temas sugeridos para compor a Base Nacional Comum Curricular e necessita de avanços. Para tal, desenvolveu-se um instrumento com 13 itens, os quais foram analisados a partir da Teoria da Resposta ao Item. Foram aplicados 1.576 instrumentos em todas as sete mesorregióes do Rio Grande do Sul, estimando-se as curvas características dos itens e as proficiências dos indivíduos. Os resultados indicaram a adequaçáo do indicador proposto e permitiram a construção dos níveis de proficiência em educação financeira.
\end{abstract}

Palavras-chave: Finanças comportamentais. Educação financeira. Escalas. Teoria da reposta ao item. Cidadania financeira.

\section{FINANCIAL EDUCATION INDICATOR: PROPOSAL OF AN INSTRUMENT FROM THE ITEM RESPONSE THEORY}

\begin{abstract}
This paper aims to construct and validate an indicator of financial education, a relevant subject that is among the themes suggested to compose the National Curricular Common Base, that needs advances. For this, an instrument was developed with thirteen items, which were analyzed from the Item Response Theory. In this context, 1576 instruments were applied in all seven mesoregions of Rio Grande do Sul, estimating the characteristic curves of the items and individuals' proficiencies. The results indicated the adequacy of the proposed indicator and allowed the construction of proficiency levels in financial education.

Keywords: Behavioral finance. Financial education. Scales. Item response theory. Financial citizenship.
\end{abstract}

\footnotetext{
*Este artigo é oriundo do projeto "Alfabetização Financeira: integrando conhecimento, atitude e comportamento financeiros" financiado pelo Conselho Nacional de Desenvolvimento Científico e Tecnológico - CNPq.

${ }^{1}$ Universidade Federal de Santa Maria - Santa Maria (RS), Brasil. E-mails: kelmara@terra.com.br; fmjunior777@yahoo.com.br; anipotrich@gmail.com

DOI: 10.1590/ES0101-73302018182568
} 


\section{INDICADOR DE EDUCACIÓN FINANCIERA: PROPOSICIÓN DE UN INSTRUMENTO A PARTIR DE LA TEORÍA DE LA RESPUESTA AL ÍTEM}

RESUMEN: Este trabajo tuvo por objetivo construir y validar un indicador de educación financiera, asunto relevante que está entre los temas sugeridos para componer la Base Nacional Común Curricular y necesita avances. Para tal, se desarrolló un instrumento con 13 ítems, los cuales fueron analizados a partir de la Teoría de la Respuesta al Ítem. Fueron aplicados 1.576 instrumentos en todas las siete mesoregiones de Rio Grande do Sul, estimándose las curvas características de los ítems y las proeficiencias de los individuos. Los resultados indicaron la adecuación del indicador propuesto y permitieron la construcción de los niveles de proeficiencia en educación financiera.

Palabras clave: Finanzas comportamentales. Educación financiera. Escalas. Teoría de la repuesta al ítem. Ciudadanía financiera.

\section{Introdução}

A alfabetização financeira vem sendo reconhecida como uma competência crítica no século 21 , sendo necessária a existência de esforços para o seu aprimoramento a fim de apoiar o crescimento econômico em qualquer economia mundial (MESSY \& MONTICONE, 2016). Nesse sentido, tanto governos de países desenvolvidos quanto de países emergentes estão preocupados com o nível de alfabetizaçáo financeira dos seus cidadãos, principalmente pela complexidade do mercado financeiro e pelo reconhecimento de que a falta de alfabetização financeira é um dos fatores que contribuiu para decisóes mal tomadas e com enormes repercussóes negativas (GERARDI; GOETTE; MEIER, 2010). Assim, diversos estudos ao redor do mundo, utilizando diferentes instrumentos e metodologias, têm apontado que grande parte da população mundial ainda sofre de analfabetismo financeiro e que medidas para sanar tal problema são urgentes (LUSARDI \& MITCHELL, 2011; ATKINSON \& MESSY, 2012; OECD, 2015; MESSY \& MONTICONE, 2016).

No Brasil, a educação financeira vem conquistando espaço na elaboração de açóes públicas a partir do Decreto no 7.397, de 22 de dezembro de 2010, que instituiu a Estratégia Nacional de Educação Financeira (ENEF), que tem como finalidade "promover a educação financeira e previdenciária e contribuir para o fortalecimento da cidadania, a eficiência e solidez do sistema financeiro nacional e a tomada de decisóes conscientes por parte dos consumidores" (BRASIL, 2010). Esse decreto busca estabelecer um conjunto de condutas e indicaçóes com o objetivo de padronizar certas diretrizes para a criação de açóes que visam atender 
a sua finalidade. Ressalta-se, também, a extensão geográfica do Brasil, bem como suas características culturais e regionais que, por meio da ENEF, busca normalizar os esforços levando em conta as diferenças existentes em todas as regiôes do país. A partir dessa iniciativa, açôes sobre a temática são compartilhadas, de forma integrada, por órgãos e entidades públicas nos âmbitos federal, estadual e municipal, além da sociedade como um todo.

Ademais, a educação financeira está entre os temas sugeridos para compor a Base Nacional Comum Curricular (BNCC), um documento de caráter normativo que pretende definir o conjunto orgânico e progressivo de aprendizagens essenciais que todos os alunos deverão desenvolver ao longo das etapas e modalidades da Educação Básica. Tem o propósito de direcionar a educação brasileira para uma formação humana integral e para a construção de uma sociedade justa, democrática e inclusiva (BRASIL, 2018).

Nesse sentido, a abordagem de temas contemporâneos como os direitos da criança e do adolescente, a educação para o trânsito, a educação ambiental e a educação financeira serão contempladas em habilidades dos componentes curriculares, que cada sistema de ensino e escolas tratará de forma contextualizada, de acordo com suas especificidades (BRASIL, 2018). Percebe-se, assim, que a educação financeira está sendo tratada de forma mais concreta nas políticas públicas ao ser incluída como um dos temas contemporâneos da BNCC, a fim de garantir o direito dos alunos a aprender e a se desenvolver, contribuindo para o incremento de sua cidadania.

Entretanto, no último levantamento do Programme for International Student Assessment (PISA), o Brasil apresentou o pior desempenho em alfabetização financeira entre todos os países e economias da Organização para a Cooperação e Desenvolvimento Econômico (OECD) participantes da avaliação. Especificamente, apenas 3\% dos estudantes brasileiros com 15 anos apresentaram proficiência no nível máximo em comparação com 12\%, em média, dos estudantes dos demais países (OECD, 2018).

Assim, apesar das pesquisas indicarem a necessidade de iniciativas nessa temática e do país estar evoluindo neste processo, um dos grandes problemas para a adoção de estratégias nacionais de educação financeira tem sido a inexistência de um modelo de mensuração universal para indicação do nível de educação financeira dos indivíduos e, consequentemente, dos focos prioritários de atuação em diferentes perfis da população. Sem um modelo adequado de avaliação do nível de educação financeira, torna-se difícil a identificação das temáticas e estratégias a serem adotadas em diferentes grupos populacionais.

Ademais, ao longo dos últimos anos surgiram diversas propostas de mensuração da educação financeira, como: o conjunto de três perguntas desenvolvidas por Lusardi e Mitchell, que são usadas em diversos estudos e tratam de taxas de juros, inflação e diversificação de risco (KNOLL \& HOUTS, 2012); a pesquisa de Clark, Lusardi e Mitchell (2015) que elaborou um instrumento deno- 
minado FinLit Survey com cinco questóes; o estudo realizado anualmente nos Estados Unidos denominado de National Financial Capability Study (NFCS, 2013); além da escala proposta pela OECD para mensurar a alfabetização financeira com 19 questóes (OECD, 2013a). Entretanto, até o momento, a maioria dessas propostas concentraram os esforços na criação das medidas, que ainda carecem de procedimentos de validação e avaliação psicométrica.

Assim, esse trabalho tem por objetivo apresentar e validar um indicador de educação financeira. Para tanto, propóe-se a utilizar a Teoria da Resposta ao Item (TRI) que possui, comparativamente à teoria clássica de medida, a vantagem de permitir a análise de características dos itens como a discriminação e a dificuldade, além de estimar a proficiência dos indivíduos considerando essas características. Destaca-se, ainda, que tal método também é utilizado para calcular as proficiências dos participantes do Exame Nacional do Ensino Médio (Enem), conforme destacam Junqueira, Martins e Lacerda (2017) em seu estudo sobre o tema.

Diante disso, a obtenção de um modelo para avaliação do nível de educação financeira é importante para os governos que estão interessados em encontrar abordagens eficazes para melhorar o nível de alfabetizaçáo financeira da população por meio da criação ou aperfeiçoamento de estratégias nacionais, com o objetivo de oferecer oportunidades de aprendizagem nos diferentes níveis educacionais (ATKINSON \& MESSY, 2012). É útil, também, para os diferentes agentes do sistema financeiro identificarem a educação financeira de seus clientes/ investidores podendo, com isso, desenvolver estratégias e produtos diferenciados.

Avanços na educação financeira são indispensáveis para a melhoria dos níveis de cidadania financeira, conceito que diz respeito aos direitos e deveres relacionados à vida financeira do cidadão, que possui a educação financeira como um de seus pilares, além da proteção ao consumidor de serviços financeiros e a inclusão financeira da população. Ademais, a literatura demonstra que a falta de educação financeira tem consequências diretas para o endividamento descontrolado e, consequentemente, para os altos níveis de inadimplência. Além dos efeitos psicológicos, sociais e de saúde que são ocasionados pela falta de educação financeira.

Assim, a implementação da educaçáo financeira em toda a base de ensino nacional é um passo importante para a melhoria da cidadania financeira dos brasileiros e consequentemente, do bem-estar financeiro da populaçáo. Uma vez que, mesmo havendo esforços de inclusão financeira nas estratégias do país, esse não conseguirá atingir seus objetivos sem que a sua população se torne educada financeiramente.

\section{Educação financeira: conceitos e instrumentos de mensuração}

Os mercados financeiros estáo cada vez mais complexos e se tornando acessíveis a mais pessoas. Com isso, a capacidade dos indivíduos para aperfeiçoa- 
rem a maneira como administram suas finanças se torna essencial. Nesse panorama, a educação financeira se tornou um tema em ascendência nas pesquisas nacionais e internacionais, uma vez que vem sendo reconhecida como um importante elemento de prevençáo contra as adversidades financeiras (OPLETALOVÁ, 2015) ao atuar como uma ferramenta de capacitação intelectual para a tomada de decisões mais responsáveis (HUSTON, 2010).

Assim, na visão de Messy e Monticone (2016), a educação financeira, também conhecida como conhecimento financeiro, é um complemento essencial para a proteção e a inclusão financeira dos consumidores. Dessa forma, devem existir esforços para o seu aprimoramento a fim de apoiar o crescimento econômico em qualquer economia mundial. De forma similar, Fernandes, Lynch e Netemeyer (2014) afirmam que a educação financeira pode ser vista como um "remédio de informaçôes" para uma combinação de políticas que inclui: oferecer mais opçóes aos indivíduos, proporcionar melhores informaçóes e fornecer incentivos para que os consumidores mudam seus comportamentos.

Além disso, a educação financeira pode ser definida como um tipo particular de capital humano que se adquire ao longo do ciclo de vida, por meio da aprendizagem de assuntos que afetam a capacidade para gerir receitas, despesas e poupança de forma eficaz (DELAVANDE; ROHWEDDER; WILLIS, 2008). Complementarmente, Huston (2010) afirma que a educaçấo financeira pode ser entendida como a capacidade de um indivíduo compreender as informaçôes financeiras vinculadas às transaçóes operacionais.

De posse desse entendimento, vários países se comprometeram e estão realizando inquéritos nacionais de alfabetização e educação financeira em toda a sua população adulta. Existem alguns esforços na busca por dados sobre os níveis de alfabetização financeira entre os jovens com idade inferior a 18 anos e não existiam, até pouco tempo, pesquisas em âmbito internacional com dados para serem comparados entre países. Essa era uma omissão grave, segundo a visão da OECD (2015), uma vez que os jovens, em breve, serão adultos que tomarão decisões financeiras ainda mais críticas e cada vez mais complexas. Assim, a disponibilidade de dados sobre a capacidade dos jovens para enfrentar esses desafios é essencial, a fim de aumentar o conhecimento sobre em quais pontos estáo preparados e quais necessitam ser aprimorados.

Por isso, a OECD incluiu, de forma opcional, aos países, uma avaliação da alfabetização financeira junto a um estudo mundial, criado em 1997, denominado de Programme for International Student Assessment (PISA), traduzido para o português como Programa Internacional de Avaliação de Alunos. Essa avaliação propóe-se a medir o quáo bem os alunos, aos 15 anos, perto do final de sua escolaridade obrigatória, adquiriram conhecimentos e habilidades essenciais para a plena participação nas sociedades modernas, centrando-se nas disciplinas básicas de ciência, leitura e matemática e, desde o levantamento de 2012, a opçáo de avaliar 
também sua alfabetizaçáo financeira. Esse programa vem sendo realizado desde o ano 2000 sendo que, no primeiro ciclo, 43 países participaram (32 em 2000 e 11 em 2002) e a mais recente pesquisa do PISA, realizada em 2015, avaliou cerca de 540 mil alunos em 72 países, incluindo o Brasil (OECD, 2018).

Assim, o PISA 2012 tornou-se o primeiro estudo internacional em grande escala para avaliar a alfabetização financeira dos jovens, considerado como o primeiro passo na construçáo da avaliação da alfabetização financeira no âmbito internacional e fornecendo um plano articulado para o desenvolvimento de itens ao projetar um instrumento e fornecer uma linguagem comum para a discussão de alfabetização financeira (OECD, 2015). No entanto, o Brasil optou por participar da avaliaçáo dessa temática somente no último levantamento, em 2015, apresentando o pior desempenho em alfabetização financeira entre todos os países participantes. Especificamente, a maioria dos estudantes brasileiros (53\%) apresentaram um desempenho abaixo do nível considerado como referência de proficiência em alfabetização financeira, além dos estudantes com vantagem socioeconômica registrarem 78 pontos a mais em alfabetização financeira do que os estudantes desfavorecidos, o equivalente a mais de um nível de proficiência (OECD, 2018). Esse cenário preocupante já vinha sendo tema de estudos e iniciativas de políticas públicas no Brasil. No ano de 2010, o Governo Federal assinou o Decreto no 7.397, que instituiu a Estratégia Nacional de Educação Financeira (ENEF), que tem como finalidade "promover a educação financeira e previdenciária e contribuir para o fortalecimento da cidadania, a eficiência e solidez do sistema financeiro nacional e a tomada de decisões conscientes por parte dos consumidores" (BRASIL, 2010). Esse decreto busca estabelecer um conjunto de condutas e indicaçóes a fim de padronizar certas diretrizes para o momento da criação de açôes que visam atender sua finalidade. Ressalta-se, também, a extensão geográfica do Brasil, bem como suas características culturais e regionais que, através da ENEF, busca normalizar os esforços em todas as regiôes do país.

Instituída como política de Estado de caráter permanente, a ENEF brasileira nasceu de uma mobilização multisetorial de 11 instituiçóes, entre elas sete órgãos e entidades governamentais e quatro organizaçóes da sociedade civil que, juntas, integram o Comitê Nacional de Educação Financeira (CONEF). Por apresentar esse diferencial, a estratégia visa valorizar ações que agreguem a iniciativa privada, a sociedade civil e o governo. Com isso, criou-se a Associação de Educação Financeira do Brasil (AEF-Brasil), uma organização sem fins lucrativos instituída em 2012, pelo CONEF, a fim de apoiar a Estratégia Nacional de Educação Financeira e que tem como missão desenvolver uma nação financeiramente educada e, como visão, ser referência mundial em educação financeira (AEF-BRASIL, 2017). No que tange às açóes promovidas por essas instituiçóes e de acordo com o último relatório anual de atividades da AEF-Brasil, referente a 2016, uma das principais metas da associação para os próximos dois anos é reunir as práticas e organizar um ecossistema de educação financeira no país. Nesse contexto, o pro- 
fessor será um dos principais pontos de conexão dessas práticas, sendo fundamental o engajamento do profissional a fim de motivar, contribuir para o letramento financeiro e, consequentemente, impactar no comportamento dos estudantes, de seus familiares e das comunidades onde estão inseridos (AEF-BRASIL, 2017).

Além disso, outra iniciativa que se destaca foi o lançamento, em 2015, do Portal da Base Nacional Comum Curricular, com o intuito de apresentar ao público o andamento da BNCC, o resultado de açóes para reformulaçáo do currículo de Educação Básica por parte de todos os estados, para o Distrito Federal, para os municípios e para a formulação de Projetos Pedagógicos das escolas. Nesse novo currículo comum, a temática da educação financeira está presente como um dos temas contemporâneos, entre os quais, destacam-se: direitos da criança e do adolescente; educação para o trânsito; educação ambiental; educação alimentar e nutricional; processo de envelhecimento, respeito e valorização do idoso; educação em direitos humanos; educação das relações étnico-raciais e ensino de história e cultura afro-brasileira, africana e indígena; saúde; vida familiar e social; educação para o consumo; educação fiscal; trabalho, ciência e tecnologia e diversidade cultural. Nesse sentido, tais temas não serão abordados como disciplinas isoladas, mas caberá aos sistemas, redes de ensino e às escolas, em suas respectivas esferas de autonomia e competência, incorporar aos currículos e às propostas pedagógicas a abordagem desses temas, preferencialmente de forma transversal e integradora (BRASIL, 2018).

No entanto, apesar do avanço, um grande desafio para a realização de pesquisas sobre educação financeira ainda é a dificuldade em determinar a melhor forma de mensurá-la, porque não há uma definição padrão na literatura (HUSTON, 2010; LUSARDI \& MITCHELL, 2014). De acordo com Schmeiser e Seligman (2013), as questóes utilizadas atualmente não foram rigorosamente testadas para garantir que estão medindo com precisão o nível de educação financeira dos indivíduos.

Apesar disso, algumas diretrizes podem ser encontradas na literatura, tanto de organizaçóes como de pesquisadores. Especificamente, o National Financial Capability Study (NFCS) é um estudo realizado para avaliar e estabelecer uma medida de referência da capacidade financeira dos adultos americanos. As questôes que mensuram a educaçáo financeira avaliam o conhecimento dos entrevistados sobre a capitalizaçáo de juros, a diversificação do risco, a inflaçáo, a relação entre os preços dos títulos e das taxas de juros, além da relação entre as taxas de juros das hipotecas e seus horizontes de pagamento (NFCS, 2013).

A OECD é outro exemplo de instituição que pesquisa a educação financeira no mundo. Seu instrumento de mensuração contém oito perguntas visando à compreensão de cálculos de juros, à relação entre inflação e retorno, à inflação e aos preços, ao risco e ao retorno, bem como ao papel da diversificação na reduçáo do risco. A pontuação da escala varia de um a oito, sendo atribuído peso um para 
cada acerto, onde valores superiores a seis são considerados os indivíduos como altamente experientes para lidar com os desafios em questôes financeiras pessoais. Pontuações entre quatro e cinco são considerados de conhecimento financeiro moderado e, valores menores que três, são considerados de conhecimento financeiro baixo (OECD, 2013a).

Lusardi e Mitchell estão entre as principais autoras de grande parte das pesquisas recentes sobre o tema, principalmente pelo desenvolvimento de um conjunto de três perguntas que são comumente usadas em diversos estudos (KNOLL \& HOUTS, 2012). As questôes compreendem três conceitos básicos de conhecimento financeiro: taxas de juros, inflação e diversificação de risco.

Algumas pesquisas utilizam essas três questôes e incorporam outras, a fim de ampliar as dimensōes que mensuram a educação financeira. Como, por exemplo, a pesquisa de Clark, Lusardi e Mitchell (2015), que elaborou um instrumento denominado de FinLit Survey, com cinco questóes, sendo as três primeiras aquelas desenvolvidas por Lusardi e Mitchell e, as duas últimas, questôes mais sofisticadas que envolvem o entendimento de como as contribuiçóes do empregador e do empregado influenciam nas acumulaçóes para o plano de aposentadoria, tendo em vista as implicaçôes fiscais dos trabalhadores antes da contribuição para os impostos.

Outra pesquisa recente que utiliza tais questóes foi desenvolvida por Lusardi (2015), ao elaborar um modelo de instrumento para mensuração da alfabetização financeira com 11 questôes. Utiliza as três perguntas citadas anteriormente e definidas como questóes básicas, além de outras oito tratadas como avançadas, questionando sobre o conhecimento dos indivíduos em: função do mercado de ações, conhecimento de fundos de investimento, relacionamento entre as taxas de juros e os preços dos títulos, diversificação do risco entre ações da empresa ou fundos de investimento, se açóes ou títulos possuem maior risco, retornos de longo prazo, maiores oscilaçóes e diversificação de riscos com diferentes ativos.

Outro instrumento, elaborado por Klapper, Lusardi e Panos (2013), incluiu quatro questóes de educação financeira que abrangem taxas de juros e juros compostos (duas perguntas), inflação (uma questão) e descontos de vendas (uma questão). De forma similar, Van Rooij, Lusardi e Alessie (2011) desenvolveram um instrumento composto por cinco perguntas tratadas como itens de conhecimento básico que mensuram as habilidades numéricas e a compreensão de conceitos como inflação, juros simples, juros compostos e o valor do dinheiro no tempo, além de outras onze questóes avançadas que abordam o conhecimento relacionado aos instrumentos financeiros complexos como ações, títulos e fundos mútuos, além do entendimento de conceitos como a diversificação de risco e do trade-off entre risco e retorno.

No contexto brasileiro, Potrich, Vieira e Kirch (2016) desenvolveram um indicador denominado de Termômetro de Alfabetização Financeira utilizando, dentre outras dimensóes, 13 questóes de múltipla escolha para mensurar a 
educaçáo financeira dos indivíduos avaliando, principalmente, os conceitos de inflação, taxa de juros, valor do dinheiro no tempo, risco, retorno, diversificação, mercado de açôes, crédito e títulos públicos.

Percebe-se, assim, que a falta de um conjunto padronizado de medidas de educação financeira consistente permitiu o surgimento de um número significativo de propostas para mensurar a educação financeira a partir de seus vários aspectos. Porém, apesar de amplitude de propostas, ainda existe uma carência de estudos que objetivem validar os indicadores propostos. Assim, entende-se ser necessário avançar em busca de um modelo que mensure de forma eficaz a educação financeira.

Ademais, a importância do desenvolvimento de indicadores não se restringe à educação financeira. Um exemplo pode ser encontrado no Indicador de Alfabetismo Funcional (Inaf), idealizado em parceria entre o Instituto Paulo Montenegro e a Organizaçáo Não Governamental (ONG) Ação Educativa e realizado com o apoio do IBOPE Inteligência, que tem o objetivo de mensurar o nível de alfabetismo da população brasileira entre 15 e 64 anos no que tange a avaliar suas habilidades e práticas de leitura, de escrita e de matemática aplicadas ao cotidiano. Em seu último estudo, em comemoração aos dez anos do indicador, analisaram as entrevistas de 2.002 pessoas entre 15 e 64 anos residentes em zonas urbanas e rurais de todas as regióes do Brasil. Os resultados apontaram que a quantidade de pessoas classificadas como alfabetizadas funcionalmente alcança $73 \%$ da população investigada. Em contrapartida, apenas $8 \%$ dos respondentes estão no último grupo de alfabetismo, revelando domínio de habilidades que praticamente não impóem restriçóes para compreender e interpretar textos em situaçóes usuais e resolver problemas envolvendo múltiplas etapas, operaçóes e informações (IPM, 2016).

\section{Método}

A pesquisa foi desenvolvida no estado do Rio Grande do Sul e abrangeu cada uma das sete mesorregiōes rio-grandenses. Considerando a amplitude da população e adotando o processo de amostragem com nível de confiança de 95\% e erro amostral de 3\%, obteve-se amostra mínima de 1.067 indivíduos. Ao final do período de coleta, alcançou-se amostra final de 1.576 pessoas distribuídas proporcionalmente ao número de habitantes em cada uma das mesorregióes.

A escala de educação financeira foi construída tendo por base questões de múltipla escolha adaptadas de Van Rooij, Lusardi e Alessie (2011), OECD (2013a), Klapper, Lusardi e Panos (2013) e pela NFCS (2013). Foi composta por 13 itens que visam explorar o nível de conhecimento em relação a questóes sobre inflação, taxa de juros, valor do dinheiro no tempo, risco, retorno, diversificação, mercado de açóes, crédito e títulos públicos. Para cada um dos 13 itens de educação financeira foi atribuído valor igual a um para a resposta correta e igual a zero para as incorretas. 
Entre os diversos modelos matemáticos utilizados nas aplicaçóes da Teoria da Resposta ao Item, nesse estudo foi utilizado o Modelo Logístico Unidimensional de Dois Parâmetros (MLU2). O modelo é adequado para o ajuste de itens politômicos (com duas ou mais categorias) com uma única opção de resposta correta, como é o caso da escala de educação financeira. Além disso, entende-se que a utilização do modelo de três parâmetros não seria necessária, uma vez que a probabilidade de acerto ao acaso pode ser descartada nas situaçóes em que o instrumento de pesquisa apresenta a categoria de resposta não sei.

Matematicamente, o modelo logístico unidimensional de dois parâmetros (MLU2) é dado pela Equação 1:

$P\left(U_{\mathrm{ij}}=1 \mid \theta_{\mathrm{j}}\right)=\frac{1}{1+\mathrm{e}^{-D_{a i}(\theta j-b i)}}$

com $i=1,2, \ldots$, I e $j=1,2, \ldots, n$

Em que:

$U_{\mathrm{ij}}=$ variável dicotômica (assume o valor 1 quando o indivíduo $j$ responde corretamente o item $i$ ou assume o valor 0 , caso contrário);

$\theta_{j}=$ o valor do traço latente (parâmetro da proficiência) do indivíduo $j$;

$P\left(U_{\mathrm{ij}}=1 \mid \theta_{\mathrm{j}}\right)=$ também chamada de Função de Resposta do Item (FRI), é a probabilidade do indivíduo $j$ responder corretamente o item $i$ dado que ele tem proficiência $\theta_{j}$, ou seja, é a proporção de respostas corretas do item $i$ dos indivíduos da populaçấo com proficiência $\theta_{j}$;

$a_{\mathrm{i}}=$ o parâmetro de discriminação (ou de inclinação) do item $i$;

$b_{\mathrm{i}}=$ o parâmetro de dificuldade (ou de posição) do item $i$;

$D=$ fator de escala constante, igual a 1 se os parâmetros dos itens são estimados na métrica da logística, ou igual a 1,7 se os parâmetros dos itens são estimados na métrica da ogiva normal;

$e=$ a conhecida constante matemática igual a 2,718281... (número de Euller);

$i=\mathrm{o}$ número total de itens;

$n=$ a quantidade total de indivíduos na amostra.

O parâmetro $a_{\mathrm{i}}$ mede a discriminação do item, onde valores baixos de $a_{\mathrm{i}}$ indicam que ele tem pouco poder de discriminação, ou seja, a probabilidade de um indivíduo responder corretamente o item é aproximadamente a mesma para indivíduos com baixo ou alto conhecimento. Já valores altos de $a_{\mathrm{i}}$ indicam que o item tem grande poder de discriminaçáo, dividindo os indivíduos praticamente em dois grupos: os que possuem proficiências abaixo do valor de $b_{\mathrm{i}}$ (com baixa 
probabilidade de acertar o item) e os que possuem proficiências acima do valor de $b_{\mathrm{i}}$ (com alta probabilidade de acertar o item). Não existe um valor exato de $a_{\mathrm{i}}$ para decidir se um item discrimina bem ou náo. Baker (2001) estabelece uma tabela de classificação onde valores de 0,01 a 0,34 são muito baixos, de 0,35 a 0,64 são baixos, de 0,65 a 1,34 são moderados, de 1,35 a 1,69 são altos e, maiores que 1,70, são muito altos.

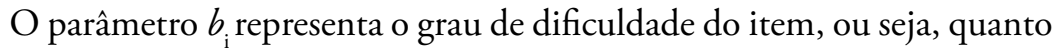
maior seu valor, mais difícil o item e indivíduos com proficiência alta terão uma boa probabilidade de acertá-lo. Matematicamente, $b_{\mathrm{i}}$ pode assumir qualquer valor entre -1 e +1 , entretanto, para valores muito altos ou baixos o item pode não ser adequado, sendo usual os valores entre -3 e +3 na escala, com média igual a zero e desvio padrão igual a um.

A relação entre a resposta prevista ao item e o traço latente do indivíduo é conhecida por meio da Curva Característica do Item (CCI). A curva apresenta a influência do parâmetro $a_{\mathrm{i}}$ (poder de discriminação) na inclinação da curva e do parâmetro $b_{\mathrm{i}}$ (posição do item na escala). $\mathrm{O}$ eixo $\mathrm{X}$ indica o valor do traço latente (proficiência), considerando uma escala com média zero e desvio padrão um, enquanto o eixo $\mathrm{Y}$ indica a probabilidade do indivíduo $j$ responder positivamente ao item dicotômico $i$, dado que ele tem proficiência $\theta_{j}$. Pode-se, ainda, analisar a quantidade de informação que um item fornece para a medida do traço latente. A Função de Informação do Item (FII) avalia a informação fornecida em cada item e reflete a qualidade do mesmo. Também é possível estimar a Função de Informação do Teste (FIT), que é simplesmente a soma das informaçôes fornecidas em cada item que compóe o instrumento.

O MLU2 é um modelo acumulativo, ou seja, a medida que o valor do traço latente aumenta, a probabilidade do indivíduo acertar o item também aumenta e vice-versa. $\mathrm{O}$ traço latente (proficiência) do indivíduo $\left(\theta_{\mathrm{j}}\right)$ é medido em uma escala arbitrária que varia teoricamente em toda a reta real. Porém, o importante nessa escala não é a sua magnitude, mas as relaçóes de ordem existentes (ANDRADE; TAVARES; VALLE, 2000).

Para estimar os parâmetros das proficiências e dos itens, processo geralmente chamado de calibração, pode-se utilizar o método da máxima verossimilhança ou métodos bayesianos. Dentre os métodos bayesianos, os mais comuns são o máximo a posteriori (MAP) e a esperança a posteriori (EAP), que foi utilizado nesse trabalho.

Após a estimação dos parâmetros, busca-se a construção da escala. Neste trabalho, optou-se pela metodologia proposta por Beaton e Allen (1992) na qual se procura, para cada nível da escala, identificar, se houver, itens cujo poder de discriminação se situa ao redor desse nível e usar estes itens para descrever o que os alunos cujas proficiências estão perto desse nível sabem e são capazes de fazer. Para a seleção dos itens âncora, utilizou-se o critério proposto por Beaton e Allen (1992). 
Sejam dois níveis âncora consecutivos $\mathrm{Y}$ e $\mathrm{Z}$ com $\mathrm{Y}<\mathrm{Z}$. Um determinado item é âncora para o nível $Z$, somente se as três condiçóes expressas na Equação 2 forem satisfeitas simultaneamente:

$$
\begin{aligned}
& P(U=1 \mid \theta=Z) \geq 0,65 \\
& P(U=1 \mid \theta=Y) \leq 0,50 \\
& P(U=1 \mid \theta=Z)-P(U=1 \mid \theta=Y) \geq 0,30
\end{aligned}
$$

Assim, para um item ser âncora em um determinado nível âncora da escala, ele precisa ser respondido corretamente por uma grande proporção de indivíduos com esse nível de habilidade e por uma proporção menor de indivíduos com o nível de habilidade imediatamente anterior. Além disso, a diferença entre a proporção de indivíduos com esses níveis de habilidade que acertam a esse item deve ser de pelo menos 30\%. Portanto, itens âncora são aqueles que caracterizam um ponto ou nível das escalas para o qual a grande maioria dos indivíduos naquele nível o acerta, ao passo que um percentual considerável de indivíduos situados ao nível abaixo da escala o erra. Esses itens têm o objetivo de discriminar pontos na escala que separam indivíduos que possuem daqueles que não possuem determinadas competências ou habilidades.

Complementarmente, buscou-se analisar a existência de associação entre o gênero e a educação formal do entrevistado e de seus pais com a classificação de proficiência. Para avaliar tais relaçóes de dependência se utilizou o teste $\chi^{2}$. Finalmente, utilizou-se a técnica de simulação para acrescentar ao indicador de educação financeira originalmente proposto duas novas questóes com parâmetro de dificuldade positivo. Assim, foi possível reestimar os níveis de proficiência e apresentar os novos níveis âncora simulados.

Para a estimação do modelo utilizou-se o software $\mathrm{R}$ versão 64 3.3.3 (R CORE TEAM, 2017), cujo pacote principal foi o Irtoys (PARTCHEV, 2016).

\section{Análise dos resultados}

Para a coleta de dados se adotou a amostragem estratificada por meio das mesorregióes do Rio Grande do Sul, e, ao final do período, foram alcançados 1.576 instrumentos válidos. Com isso, inicialmente é importante caracterizá-la por meio das questóes relacionadas ao gênero, idade, estado civil, escolaridade, ascendência, ocupação, entre outros. Para realizar a análise dessas questões se utilizou a estatística descritiva, considerando a frequência e o percentual em cada questão. Os resultados estão expressos na Tabela 1. 


\section{Tabela 1}

Perfil dos respondentes segundo as variáveis: gênero, estado civil, estudante, dependentes, escolaridade, escolaridade do pai, escolaridade da mãe, ascendência e ocupação.

\begin{tabular}{|c|c|c|c|}
\hline Variável & Alternativas & Frequência & Percentual $^{1}$ \\
\hline \multirow{2}{*}{ Gênero } & Masculino & 690 & $44,00 \%$ \\
\hline & Feminino & 877 & $56,00 \%$ \\
\hline \multirow{3}{*}{ Estado civil } & Solteiro(a) & 969 & $61,90 \%$ \\
\hline & Casado(a) / União estável & 528 & $33,70 \%$ \\
\hline & Separado(a) / Divorciado(a) / Viúvo(a) & 68 & $4,30 \%$ \\
\hline \multirow{2}{*}{ Estudante } & Não & 752 & $48,20 \%$ \\
\hline & Sim & 807 & $51,80 \%$ \\
\hline \multirow{2}{*}{ Dependentes } & Não & 1075 & $70,40 \%$ \\
\hline & Sim & 453 & $29,60 \%$ \\
\hline \multirow{6}{*}{ Escolaridade } & Ensino fundamental & 96 & $6,20 \%$ \\
\hline & Ensino médio & 555 & $35,80 \%$ \\
\hline & Ensino superior & 634 & $40,90 \%$ \\
\hline & Curso técnico & 102 & $6,60 \%$ \\
\hline & Especialização ou MBA & 117 & $7,50 \%$ \\
\hline & Mestrado / Doutorado / Pós-doutorado & 46 & $3,00 \%$ \\
\hline \multirow{6}{*}{$\begin{array}{l}\text { Escolaridade } \\
\text { do pai }\end{array}$} & Ensino fundamental & 741 & $48,10 \%$ \\
\hline & Ensino médio & 410 & $26,60 \%$ \\
\hline & Ensino superior & 252 & $16,40 \%$ \\
\hline & Curso técnico & 70 & $4,50 \%$ \\
\hline & Especialização ou MBA & 34 & $2,20 \%$ \\
\hline & Mestrado / Doutorado / Pós-doutorado & 33 & $2,10 \%$ \\
\hline \multirow{6}{*}{$\begin{array}{l}\text { Escolaridade } \\
\text { da máe }\end{array}$} & Ensino fundamental & 689 & $44,30 \%$ \\
\hline & Ensino médio & 418 & $26,80 \%$ \\
\hline & Ensino superior & 264 & $17,00 \%$ \\
\hline & Curso técnico & 71 & $4,60 \%$ \\
\hline & Especialização ou MBA & 75 & $4,80 \%$ \\
\hline & Mestrado / Doutorado / Pós-doutorado & 40 & $2,60 \%$ \\
\hline \multirow{6}{*}{ Ascendência } & Brasileiro(a) & 1.065 & $69,60 \%$ \\
\hline & Português(a) & 33 & $2,20 \%$ \\
\hline & Alemão(a) & 135 & $8,80 \%$ \\
\hline & Italiano(a) & 227 & $14,80 \%$ \\
\hline & Não sei & 29 & $1,90 \%$ \\
\hline & Outra & 41 & $2,70 \%$ \\
\hline
\end{tabular}




\section{Tabela 1}

Continuação.

\begin{tabular}{l|c|c|c}
\hline Variável & Alternativas & Frequência & Percentual $^{\mathbf{1}}$ \\
\hline \multirow{4}{*}{ Ocupaçáo } & Funcionário(a) público(a) & 247 & $16,00 \%$ \\
\cline { 2 - 4 } & Empregado(a) assalariado(a) & 542 & $35,00 \%$ \\
\cline { 2 - 4 } & Profissional liberal & 65 & $4,20 \%$ \\
\cline { 2 - 4 } & Autônomo(a) & 180 & $11,60 \%$ \\
\cline { 2 - 4 } & Aposentado(a) & 311 & $2,70 \%$ \\
\cline { 2 - 4 } & Náo trabalha & 161 & $10,40 \%$ \\
\hline \multirow{2}{*}{ Idade } & Outra Idade Média = 30 anos \\
\hline
\end{tabular}

${ }^{1}$ Os percentuais considerados correspondem ao percentual válido de respondentes. Caso algum respondente não tenha respondido, o percentual é automaticamente ajustado ao total.

Ao analisar o perfil dos respondentes, percebe-se que a maioria pertence ao gênero feminino (56\%), é solteiro(a) (61,9\%), além de apresentar idade média de 30 anos. No entanto, obteve-se uma variação de idades entre os indivíduos pesquisados que oscilou entre 18 e 80 anos. Averiguou-se, ainda, que $70,4 \%$ dos respondentes não possuem dependentes (pessoas que dependam da renda do indivíduo). Por outro lado, os demais (29,6\%) apontam que possuem dependentes, sendo em sua maioria um dependente $(50,4 \%)$, seguido dos que possuem dois dependentes $(35,1 \%)$.

No que tange à escolaridade, a maior frequência se intitula com um nível de escolaridade de ensino superior (40,9\%), seguidos dos intitulados de ensino médio $(35,8 \%)$ e apenas $3 \%$ possuem pós-graduação. Constatou-se, ainda, que $51,8 \%$ estudam atualmente e, desses, a maioria pertence a cursos que possuem em sua grade curricular disciplinas relativas às Finanças como, por exemplo, Matemática, Matemática Financeira e Administração Financeira, representando 82,1\% do total de estudantes. Além disso, mais da metade dos indivíduos que estudam estáo inseridos nos primeiros quatro semestres do curso superior.

Ao serem questionados quanto ao nível de escolaridade de seus pais, nota-se que tanto o pai $(48,1 \%)$, quanto a mãe $(44,3 \%)$ da maioria dos indivíduos possui ensino fundamental, seguidos de pais que possuem ensino médio, com índice $26,6 \%$ para a escolaridade do pai e $26,8 \%$ para a da mãe. Tais resultados indicam um baixo nível de escolaridade dos pais.

Tendo em vista a variável ascendência, nota-se que os respondentes apontam pertencer à ascendência brasileira $(69,6 \%)$, seguidos dos intitulados com ascendência italiana $(14,8 \%)$. Para finalizar a caracterização da amostra, indagou-se, ainda, sobre a ocupação dos indivíduos. As ocupaçóes predominantes 
são de empregados assalariados (35\%), funcionários públicos (16\%) e autônomos $(11,6 \%)$, além de apresentar uma parcela relevante de indivíduos que não trabalham $(20,1 \%)$ e que apresentam outras ocupaçóes $(10,4 \%)$ sendo, em sua maioria, estudantes e bolsistas. Após o conhecimento do perfil dos entrevistados, investigou-se sobre a origem e a responsabilidade financeira através de questóes sobre a renda mensal própria, a renda mensal familiar, a fonte de renda e o responsável por prover os recursos e realizar o pagamento das contas familiares, as quais estão apresentadas na Tabela 2 .

\section{Tabela 2}

Origem e responsabilidade financeira segundo as variáveis: renda mensal própria, renda mensal familiar, fonte de renda, responsável por prover os recursos e por realizar o pagamento das contas.

\begin{tabular}{|c|c|c|c|}
\hline Variável & Alternativas & Frequência & Percentual $^{1}$ \\
\hline \multirow{8}{*}{$\begin{array}{l}\text { Faixa de renda } \\
\text { média mensal } \\
\text { própria }\end{array}$} & Até $\mathrm{R} \$ 700,00$ & 315 & $20,30 \%$ \\
\hline & Entre $\mathrm{R} \$ 700,01$ e $\mathrm{R} \$ 1.400,00$ & 446 & $28,70 \%$ \\
\hline & Entre $\mathrm{R} \$ 1.400,01$ e $\mathrm{R} \$ 2.100,00$ & 242 & $15,60 \%$ \\
\hline & Entre $\mathrm{R} \$ 2.100,01$ e $\mathrm{R} \$ 3.500,00$ & 191 & $12,30 \%$ \\
\hline & Entre $\mathrm{R} \$ 3.500,01$ e $\mathrm{R} \$ 7.000,00$ & 129 & $8,30 \%$ \\
\hline & Entre R\$ 7.000,01 e R \$ 14.000,00 & 34 & $2,20 \%$ \\
\hline & Mais de $\mathrm{R} \$ 14.000,00$ & 6 & $0,40 \%$ \\
\hline & Não possuo renda própria & 190 & $12,20 \%$ \\
\hline \multirow{7}{*}{$\begin{array}{l}\text { Faixa de renda } \\
\text { média mensal } \\
\text { familiar }\end{array}$} & Até R\$ 700,00 & 45 & $2,90 \%$ \\
\hline & Entre $R \$ 700,01$ e $R \$ 1.400,00$ & 176 & $11,40 \%$ \\
\hline & Entre $\mathrm{R} \$ 1.400,01$ e $\mathrm{R} \$ 2.100,00$ & 243 & $15,70 \%$ \\
\hline & Entre $\mathrm{R} \$ 2.100,01$ e $\mathrm{R} \$ 3.500,00$ & 389 & $25,20 \%$ \\
\hline & Entre $R \$ 3.500,01$ e $R \$ 7.000,00$ & 425 & $27,50 \%$ \\
\hline & Entre R \$ 7.000,01 e R \$ 14.000,00 & 194 & $12,50 \%$ \\
\hline & Mais de $\mathrm{R} \$ 14.000,00$ & 74 & $4,80 \%$ \\
\hline \multirow{6}{*}{$\begin{array}{l}\text { Qual a } \\
\text { principal fonte } \\
\text { de renda da sua } \\
\text { família? }\end{array}$} & Salário & 1.041 & $67,20 \%$ \\
\hline & Aposentadoria ou pensão & 112 & $7,20 \%$ \\
\hline & Benefícios/subsídios do governo & 13 & $0,80 \%$ \\
\hline & $\begin{array}{l}\text { Ganhos próprios ou provenientes do } \\
\text { negócio da família }\end{array}$ & 368 & $23,80 \%$ \\
\hline & $\begin{array}{c}\text { Auxílio de membros da } \\
\text { família que não vivem na casa }\end{array}$ & 9 & $0,60 \%$ \\
\hline & Auxílio de outra(s) pessoa(s) & 6 & $0,40 \%$ \\
\hline
\end{tabular}


Tabela 2

Continuação.

\begin{tabular}{|c|c|c|c|}
\hline Variável & Alternativas & Frequência & Percentual $^{1}$ \\
\hline \multirow{6}{*}{$\begin{array}{l}\text { Quem é o } \\
\text { responsável } \\
\text { por prover } \\
\text { recursos para o } \\
\text { pagamento das } \\
\text { contas na sua } \\
\text { família? }\end{array}$} & Você & 254 & $16,20 \%$ \\
\hline & Você e seu(a) parceiro(a) & 416 & $26,50 \%$ \\
\hline & Seu(a) parceiro(a) & 42 & $2,70 \%$ \\
\hline & Você e outro membro da família & 235 & $15,00 \%$ \\
\hline & Seus pais & 611 & $39,00 \%$ \\
\hline & Outra pessoa & 10 & $0,60 \%$ \\
\hline \multirow{6}{*}{$\begin{array}{l}\text { Quem é } \\
\text { responsável } \\
\text { por realizar o } \\
\text { pagamento das } \\
\text { contas na sua } \\
\text { família? }\end{array}$} & Você & 327 & $20,80 \%$ \\
\hline & Você e seu(a) parceiro(a) & 364 & $23,20 \%$ \\
\hline & Seu(a) parceiro(a) & 47 & $3,00 \%$ \\
\hline & Você e outro membro da família & 238 & $15,20 \%$ \\
\hline & Seus pais & 584 & $37,20 \%$ \\
\hline & Outra pessoa & 10 & $0,60 \%$ \\
\hline
\end{tabular}

${ }^{1}$ Os percentuais considerados correspondem ao percentual válido de respondentes. Caso algum respondente náo tenha respondido, o percentual é automaticamente ajustado ao total.

Ao realizar a análise dos dados referentes às origens e responsabilidades financeiras, percebe-se que quase metade dos indivíduos possuem uma renda média mensal própria de até $\mathrm{R} \$ 1.400,00$ (49\%) e que apenas 10,9\% dos respondentes possuem uma renda acima de $\mathrm{R} \$ 3.500,00$ mensais. Além disso, uma parcela expressiva da amostra $(12,2 \%)$ não possui renda, fato justificado, principalmente, pelos estudantes que ainda são dependentes financeiramente de seus pais e/ou familiares. Já ao analisar a renda média mensal familiar, encontra-se mais da metade dos indivíduos pertencentes à faixa de renda que varia entre $\mathrm{R} \$ 2.100,01$ e $\mathrm{R} \$ 7.000,00$ (52,7\%) e apenas 14,3\% possuem renda familiar de até $\mathrm{R} \$ 1.400,00$, tendo como principais fontes de renda os salários $(67,2 \%)$ e ganhos próprios ou do negócio da família $(23,80 \%)$. Esses resultados demonstram que, no contexto familiar, o respondente não é o único a prover recursos para o sustento da família, uma vez que as mulheres e jovens estão cada vez mais inseridos no mercado de trabalho. No período entre 2000 e 2010, as mulheres brasileiras responsáveis pela família passaram de $22,2 \%$ para $37,3 \%$, segundo o censo do Instituto Brasileiro de Geografia e Estatísticas de 2010 (IBGE, 2010).

Sendo assim, indagou-se sobre a responsabilidade por prover recursos para o pagamento das contas da família e a responsabilidade por realizar o pagamento das mesmas. Quanto à responsabilidade por prover recursos, apenas 16,2\% afirmam serem os únicos responsáveis; no entanto, 26,5\% indicam a divisão da responsabilidade com seu(a) parceiro(a) e, para 39\%, essa responsabilidade ainda é dos pais. Forma similar acontece quanto à responsabilidade por realizar o paga- 
mento das contas, quando $37,2 \%$ afirmam que tal responsabilidade é dos pais, seguido pela divisão entre o respondente e seu(a) parceiro(a) $(23,2 \%)$.

Com isso, após conhecer as características dos indivíduos pesquisados, optou-se por analisar a resposta dos respondentes às questóes que compóem o indicador de educação financeira, elaborado com dois conjuntos de questôes. O primeiro (educação financeira básica) foi composto de oito itens e visou medir habilidades financeiras básicas. Já o segundo grupo (educação financeira avançada), composto de cinco itens, buscou explorar o nível de conhecimento em relação a instrumentos financeiros complexos como ações, títulos públicos, inflação e diversificação de risco. Assim, para cada questão foi atribuído o valor zero para as respostas erradas e o valor um para as respostas corretas. Os itens da escala e a frequência de respostas corretas e incorretas e daquelas referentes às perguntas que os entrevistados não souberam responder, além do percentual de acertos, estão demonstradas na Tabela 3.

\section{Tabela 3}

Frequência e percentual válido na escala do indicador de educação financeira.

\begin{tabular}{|c|c|c|c|c|}
\hline Item & Questóes & Alternativas & Frequência & Percentual \\
\hline \multirow{4}{*}{1} & \multirow{4}{*}{$\begin{array}{l}\text { Suponha que você tenha } \mathrm{R} \$ \\
100,00 \text { em uma conta poupança } \\
\text { a uma taxa de juros de } 10 \% \text { ao } \\
\text { ano. Depois de } 5 \text { anos, qual o } \\
\text { valor que você terá na poupança? } \\
\text { Considere que não tenha sido } \\
\text { depositado e nem retirado } \\
\text { dinheiro. }\end{array}$} & ${ }^{*}$ Mais do que $\mathrm{R} \$ 150,00$ & 883 & $56.75 \%$ \\
\hline & & Exatamente R\$ 150,00. & 432 & $27.76 \%$ \\
\hline & & Menos do que R\$150,00. & 103 & $6.62 \%$ \\
\hline & & Não sei. & 138 & $8.87 \%$ \\
\hline \multirow{4}{*}{2} & \multirow{4}{*}{$\begin{array}{l}\text { Suponha que José herde } \mathrm{R} \$ \\
10.000,00 \text { hoje e Pedro herde } \mathrm{R} \$ \\
10.000,00 \text { daqui a } 3 \text { anos. Devido } \\
\text { à herança, quem ficará mais rico? }\end{array}$} & *José. & 775 & $49.90 \%$ \\
\hline & & Pedro. & 160 & $10.30 \%$ \\
\hline & & São igualmente ricos. & 337 & $21.70 \%$ \\
\hline & & Não sei. & 281 & $18.09 \%$ \\
\hline \multirow{4}{*}{3} & \multirow{4}{*}{$\begin{array}{l}\text { Imagine que a taxa de juros } \\
\text { incidente sobre sua conta } \\
\text { poupança seja de } 6 \% \text { ao ano e a } \\
\text { taxa de inflação seja de } 10 \% \text { ao } \\
\text { ano. Após } 1 \text { ano, o quanto você } \\
\text { será capaz de comprar com o } \\
\text { dinheiro dessa conta? Considere } \\
\text { que não tenha sido depositado e } \\
\text { nem retirado dinheiro. }\end{array}$} & Mais do que hoje. & 147 & $9.53 \%$ \\
\hline & & Exatamente o mesmo. & 52 & $3.37 \%$ \\
\hline & & *Menos do que hoje. & 976 & $63.29 \%$ \\
\hline & & Não sei. & 367 & $23.80 \%$ \\
\hline
\end{tabular}


Tabela 3

Continuação.

\begin{tabular}{|c|c|c|c|c|}
\hline Item & Questóes & Alternativas & Frequência & Percentua \\
\hline \multirow{4}{*}{4} & \multirow{4}{*}{$\begin{array}{l}\text { Suponha que no ano de } 2014 \\
\text { sua renda dobrará e os preços de } \\
\text { todos os bens também dobraráo. } \\
\text { Em } 2014 \text {, o quanto você será } \\
\text { capaz de comprar com a sua } \\
\text { renda? }\end{array}$} & Mais do que hoje. & 216 & $13.84 \%$ \\
\hline & & ${ }^{*}$ Exatamente o mesmo. & 990 & $63.42 \%$ \\
\hline & & Menos do que hoje. & 192 & $12.30 \%$ \\
\hline & & Não sei. & 163 & $10.44 \%$ \\
\hline \multirow{4}{*}{5} & \multirow{4}{*}{$\begin{array}{l}\text { Considerando-se um longo } \\
\text { período de tempo (ex.: } 10 \text { anos), } \\
\text { qual ativo, normalmente, oferece } \\
\text { maior retorno? }\end{array}$} & Poupança. & 415 & $26.65 \%$ \\
\hline & & *Açốes. & 424 & $27.23 \%$ \\
\hline & & Títulos públicos. & 307 & $19.72 \%$ \\
\hline & & Não sei. & 411 & $26.40 \%$ \\
\hline \multirow{4}{*}{6} & \multirow{4}{*}{$\begin{array}{l}\text { Normalmente, qual ativo } \\
\text { apresenta as maiores oscilaçóes ao } \\
\text { longo do tempo? }\end{array}$} & Poupança. & 64 & $4.10 \%$ \\
\hline & & *Açóes. & 1124 & $72.05 \%$ \\
\hline & & Títulos públicos. & 72 & $4.62 \%$ \\
\hline & & Não sei. & 300 & $19.23 \%$ \\
\hline \multirow{4}{*}{7} & \multirow{4}{*}{$\begin{array}{l}\text { Quando um investidor distribui } \\
\text { seu investimento entre diferentes } \\
\text { ativos, o risco de perder dinheiro: }\end{array}$} & Aumenta. & 298 & $19.16 \%$ \\
\hline & & ${ }^{*}$ Diminui. & 892 & $57.36 \%$ \\
\hline & & Permanece inalterado. & 65 & $4.18 \%$ \\
\hline & & Não sei. & 300 & $19.29 \%$ \\
\hline \multirow{3}{*}{8} & \multirow{3}{*}{$\begin{array}{l}\text { Um empréstimo com duração } \\
\text { de } 15 \text { anos normalmente exige } \\
\text { pagamentos mensais maiores do } \\
\text { que um empréstimo de } 30 \text { anos, } \\
\text { mas o total de juros pagos ao final } \\
\text { do empréstimo será menor. Essa } \\
\text { afirmação é: }\end{array}$} & *Verdadeira. & 1001 & $64.04 \%$ \\
\hline & & Falsa. & 305 & $19.51 \%$ \\
\hline & & Não sei. & 257 & $16.44 \%$ \\
\hline \multirow{5}{*}{9} & \multirow{5}{*}{$\begin{array}{l}\text { Suponha que você realizou um } \\
\text { empréstimo de } \mathrm{R} \$ 10.000,00 \\
\text { para ser pago após um ano e o } \\
\text { custo total com os juros é } \mathrm{R} \$ \\
600,00 \text {. A taxa de juros que você } \\
\text { irá pagar nesse empréstimo é de: }\end{array}$} & $0,3 \%$. & 21 & $1.35 \%$ \\
\hline & & $0,6 \%$ & 217 & $13.96 \%$ \\
\hline & & $3 \%$ & 53 & $3.41 \%$ \\
\hline & & $* 6 \%$ & 993 & $63.90 \%$ \\
\hline & & Não sei. & 270 & $17.37 \%$ \\
\hline \multirow{3}{*}{10} & \multirow{3}{*}{$\begin{array}{l}\text { Suponha que você viu o mesmo } \\
\text { televisor em duas lojas diferentes } \\
\text { pelo preço inicial de } \mathrm{R} \$ 1.000 .00 \text {. } \\
\text { A loja A oferece um desconto } \\
\text { de R } \$ 150,00 \text {, enquanto a loja } \\
\text { B oferece um desconto de } 10 \% \text {. } \\
\text { Qual é a melhor alternativa? }\end{array}$} & $\begin{array}{c}{ }^{*} \text { Comprar na loja A } \\
\text { (desconto de R\$ 150,00). }\end{array}$ & 1404 & $90.00 \%$ \\
\hline & & $\begin{array}{l}\text { Comprar na loja B } \\
\text { (desconto de } 10 \%) \text {. }\end{array}$ & 64 & $4.10 \%$ \\
\hline & & Não sei. & 92 & $5.90 \%$ \\
\hline
\end{tabular}


Tabela 3

Continuação.

\begin{tabular}{|c|c|c|c|c|}
\hline Item & Questóes & Alternativas & Frequência & Percentual \\
\hline \multirow{5}{*}{11} & \multirow{5}{*}{$\begin{array}{l}\text { Imagine que cinco amigos } \\
\text { recebem uma doaçáo de } \\
\mathrm{R} \$ 1.000,00 \text { e precisam dividir } \\
\text { o dinheiro igualmente entre eles. } \\
\text { Quanto cada um vai obter? }\end{array}$} & 100. & 14 & $0.89 \%$ \\
\hline & & $* 200$. & 1425 & $90.94 \%$ \\
\hline & & 1000. & 45 & $2.87 \%$ \\
\hline & & 5000. & 13 & $0.83 \%$ \\
\hline & & Não sei. & 70 & $4.47 \%$ \\
\hline \multirow{3}{*}{12} & \multirow{3}{*}{$\begin{array}{l}\text { Um investimento com alta taxa } \\
\text { de retorno terá alta taxa de risco. } \\
\text { Essa afirmaçáo é: }\end{array}$} & *Verdadeira. & 1094 & $70.40 \%$ \\
\hline & & Falsa. & 189 & $12.16 \%$ \\
\hline & & Não sei. & 271 & $17.44 \%$ \\
\hline \multirow{3}{*}{13} & \multirow{3}{*}{$\begin{array}{l}\text { Quando a inflação aumenta, } \\
\text { o custo de vida sobe. Essa } \\
\text { afirmaçáo é: }\end{array}$} & *Verdadeira. & 1378 & $88.05 \%$ \\
\hline & & Falsa. & 67 & $4.28 \%$ \\
\hline & & Não sei. & 120 & $7.67 \%$ \\
\hline
\end{tabular}

${ }^{1}$ Os percentuais considerados correspondem ao percentual de acertos válidos sobre o total de respostas. Caso algum respondente não tenha respondido, o percentual é automaticamente ajustado ao total; * resposta correta da questão.

Os itens $1,2,3,4,8,9,10$ e 11 são referentes às temáticas pertencentes à educaçáo financeira básica, que teve por objetivo mensurar o conhecimento dos indivíduos quanto a aspectos corriqueiros como taxas de juros simples e compostos, valor do dinheiro no tempo e operaçóes matemáticas simples. Os dois únicos itens que apresentaram um alto índice de acerto (acima de $80 \%$ ) foram os que abordaram operaçóes matemáticas simples, ao se perguntar sobre uma simples divisão ( $\mathrm{R} \$ 1.000,00$ / 5 amigos) e diferenciar a melhor alternativa entre duas opçóes de desconto.

O segundo grupo de itens $(5,6,7,12$ e 13), referente à educação financeira avançada, buscou explorar a proficiência em relação a instrumentos financeiros mais complexos. Os dois itens que apresentaram maiores percentuais de acerto tratam da oscilação na rentabilidade das açóes ao longo do tempo $(72,05 \%)$ e do entendimento da relação entre risco e retorno $(70,4 \%)$. Um percentual baixo de acerto foi observado no item referente ao ativo que oferece maior retorno $(27,23 \%)$, sendo que $26,4 \%$ dos indivíduos não souberam respondê-lo.

Cabe destacar, ainda, que o único item considerado de educação financeira avançada que obteve um alto percentual de acerto foi o que abordava o entendimento do aumento do custo de vida ocasionado pelo aumento da inflação $(88,05 \%)$. Esse resultado pode ser justificado pela situação vivida no Brasil alguns anos atrás, com altas oscilações diárias na taxa de inflação quando, por esse motivo, a população presenciou o aumento do custo de vida. Geralmente os indivíduos tendem a acertar mais os itens cujas temáticas podem ser vistas e acompanhadas 
quase que diariamente nos noticiários ou até vivenciadas em situaçóes de compra de mercadorias. Ao analisar o número de acertos por respondente, constatou-se que $2,22 \%$ dos respondentes não acertaram ou não souberam responder a nenhum dos treze itens sugeridos e somente 3,87\% acertaram todos os itens. Porém, mais da metade dos indivíduos respondeu corretamente no mínimo 66\% das perguntas.

Em seguida, passou-se à análise do indicador de educação financeira à luz da Teoria da Resposta ao Item. Devido à pressuposição de unidimensionalidade do MLU2, optou-se por utilizar a análise fatorial de dados categóricos para verificar o atendimento da pressuposição. $\mathrm{O}$ primeiro fator da análise fatorial apresentou um percentual de variância explicada de 44,71\%, valor bastante superior ao mínimo de $20 \%$ sugerido por Reckase (1979) como critério de aceitação da unidimensionalidade da escala, comprovando assim a adequação do MLU2.

Dos trezes itens apresentados, optou-se por excluir do modelo o item 2 "Suponha que José herde R\$ 10.000,00 hoje e Pedro herde R \$10.000,00 daqui a 3 anos. Devido à herança, quem ficará mais rico?” com parâmetro de discriminação igual a 0,6258 e o item 5 "Considerando-se um longo período de tempo (ex.: 10 anos), qual ativo, normalmente, oferece maior retorno?" pois ambos apresentaram parâmetro de discriminação considerados baixos, segundo critério de Baker (2001). Assim, a Tabela 4 apresenta os resultados para a estimação com os onze parâmetros restantes.

\section{Tabela 4}

Coeficientes e erros-padróes dos parâmetros de

dificuldade e discriminação do indicador de educação financeira.

\begin{tabular}{l|c|c|c|c}
\hline \multirow{2}{*}{ Item } & \multicolumn{2}{|c|}{$\mathbf{a}_{\mathbf{i}}$} & \multicolumn{2}{c}{$\mathbf{b}_{\mathbf{i}}$} \\
\cline { 2 - 5 } & Coeficiente & Erro padráo & Coeficiente & Erro padráo \\
\hline 1 & 0,8232 & 0,0763 & $-0,3328$ & 0,0749 \\
\hline 3 & 1,6627 & 0,1244 & $-0,4227$ & 0,0488 \\
\hline 4 & 1,1065 & 0,0901 & $-0,5827$ & 0,0671 \\
\hline 7 & 1,7214 & 0,1301 & $-0,7791$ & 0,0565 \\
\hline 8 & 1,8777 & 0,1421 & $-0,2143$ & 0,0434 \\
\hline 9 & 1,1069 & 0,0905 & $-0,6160$ & 0,0683 \\
\hline 10 & 1,3702 & 0,1050 & $-0,5158$ & 0,0566 \\
\hline 12 & 2,6705 & 0,2534 & $-1,4641$ & 0,0712 \\
\hline 13 & 2,2237 & 0,2002 & $-1,6625$ & 0,0858 \\
\hline
\end{tabular}


Quanto à discriminação, observa-se que o item 1 é o de menor poder discriminatório. Já os itens 11, 13 e 10, respectivamente, são os de maiores discriminação, ou seja, discriminam os respondentes entre os que possuem conhecimento abaixo do parâmetro e aqueles com conhecimento acima do parâmetro.

Quanto ao parâmetro de dificuldade, observa-se que todos os itens apresentaram valores negativos. Assim, quanto menores os valores, menor a dificuldade do item. Portanto, os itens 11 "Imagine que cinco amigos recebem uma doação de $\mathrm{R} \$ 1.000,00$ e precisam dividir o dinheiro igualmente entre eles. Quanto cada um vai obter?" e 10 "Suponha que você viu o mesmo televisor em duas lojas diferentes pelo preço inicial de $\mathrm{R} \$ 1.000 .00$. A loja A oferece um desconto de $\mathrm{R} \$ 150,00$, enquanto a loja B oferece um desconto de $10 \%$. Qual é a melhor alternativa?” são os itens mais fáceis do indicador de educação financeira.

Já o item 7 "Quando um investidor distribui seu investimento entre diferentes ativos, o risco de perder dinheiro" é o mais difícil do instrumento. Tais resultados são consistentes com os estudos de educação financeira, já que as questôes 10 e 11 são considerados itens de conhecimento básico e a questão 7 é um item de conhecimento avançado, assim como na classificação das questóes encontradas nas pesquisas de Van Rooij, Lusardi e Alessie (2011) e Lusardi (2015).

A Figura 1 apresenta as Curvas Características dos Itens (CCIs), onde é possível verificar a posição e a discriminação de cada um. Observa-se que vários itens se apresentam dentro de um intervalo compreendido entre -4 e +2 , ou seja, possuem um poder semelhante de discriminação. As curvas características encontram-se, em sua maioria, na parte negativa da escala indicando que, de maneira geral, os itens têm maior capacidade de discriminar os indivíduos com educação financeira abaixo da média do que os indivíduos com proficiência acima da média. Ressalta-se que pesquisas vêm indicando um baixo nível de educação da população, ou seja, é mais comum encontrarmos indivíduos com proficiência abaixo da média.

No entanto, o baixo nível de educação financeira encontrado não é exclusividade dessa pesquisa. Nos últimos anos, diferentes pesquisadores vêm se dedicando a esses índices, tanto de estudantes quanto da população em geral, e vem obtendo resultados bastante preocupantes com níveis insatisfatórios de conhecimento, sejam em questões de gestão financeira pessoal ou em questões mais específicas como crédito, empréstimo, poupança e investimento (VAN ROOIj; LUSARDI; ALESSIE, 2011; BARCELLOS et al., 2016).

Em seguida, buscou-se avaliar as funções de informação dos itens e do instrumento.

A partir da Figura 2, identifica-se que na Curva de Informação Total obtida pela soma, têm-se as funçóes de informação de todos os itens que compóem a prova, sendo que os itens que possuem maior valor de informação estão localizados no inter- 


\section{Figura 1}

Curvas características dos itens do indicador de educaçáo financeira.

Item 1

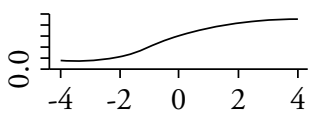

Ability

Item 6

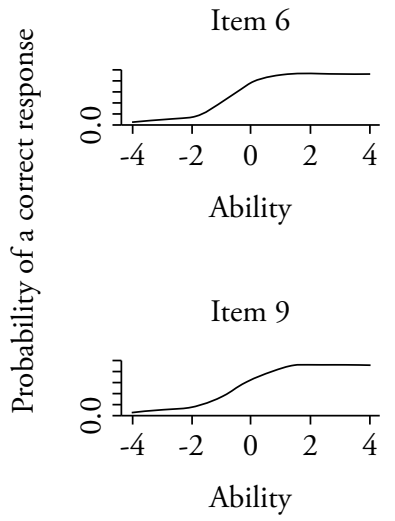

Item 12

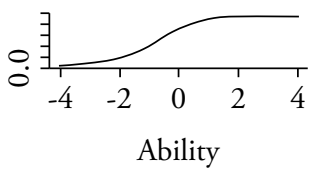

Item 3

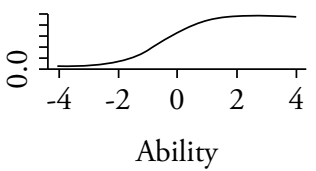

Item 7

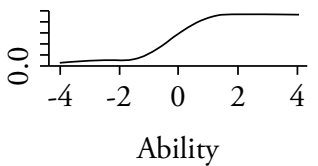

Item 10

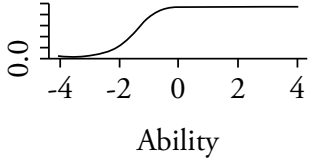

Item 13

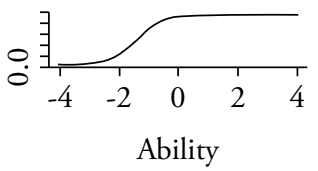

Item 4

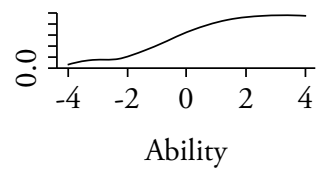

Item 8

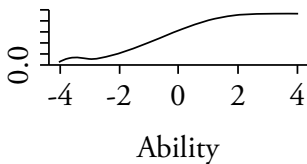

Item 11

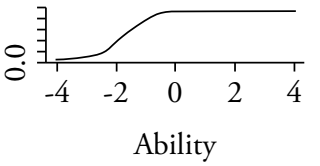

Figura 2

Função de informação total e por item do indicador de educação financeira.

Função de informação total

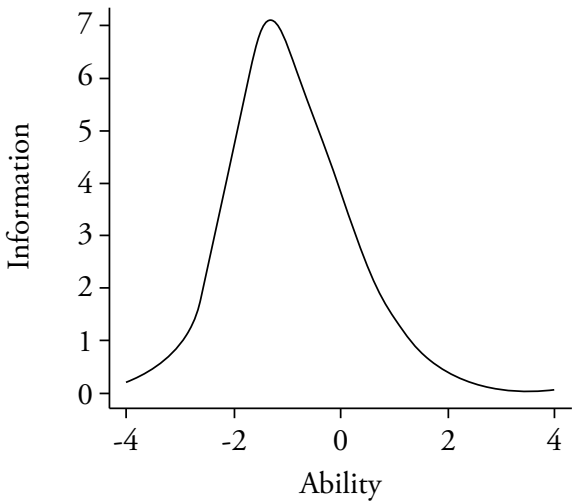

Função de informação do item

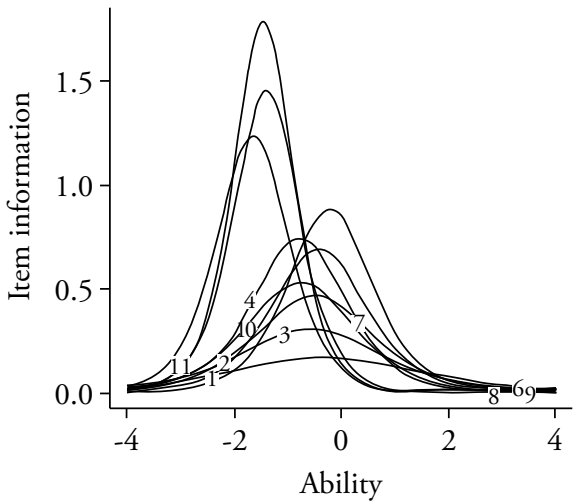


valo onde a proficiência assume valores entre $-2 \mathrm{e}+1$. Assim, constata-se que o instrumento apresenta um maior nível de informação para os indivíduos com proficiência nesse intervalo. Considerando que a escala de proficiência possui média zero e desvio padrão um, o instrumento apresenta um maior nível de informação para indivíduos com proficiências entre dois desvios-padróes abaixo e um desvio acima da média.

$\mathrm{Na}$ figura das CCIs se percebe que existe uma grande variação no que diz respeito à posição do ponto de inflexão de cada curva, ponto que está diretamente relacionado ao parâmetro de dificuldade de cada item, ou seja, a escala possui itens com diferentes graus de dificuldade. Observa-se também a existência de variaçôes na inclinação que cada curva apresenta, inclinação que corresponde ao valor que o parâmetro assume, ou seja, parâmetro de discriminação.

Após a obtenção dos parâmetros, estimou-se o nível de habilidade, ou seja, o conhecimento de cada indivíduo. O pacote Irtoys oferece três métodos de estimação: por máxima verossimilhança, por máximo a posteriori e por esperança a posteriori, escolhido para essa estimação. A Tabela 5 apresenta os níveis âncora, seus respectivos limites de proficiência, o percentual de entrevistados e os itens âncora. A Figura 3 mostra a distribuição de frequência do indicador de educação financeira. Observa-se, pela Tabela 5 , que $41,12 \%$ dos indivíduos possuem educação financeira em torno de zero, ou seja, possuem uma proficiência média. Visualiza-se, ainda, que existem mais indivíduos com proficiência acima da média do que abaixo da média. Assim, a curva de proficiência (Figura 3) se mostra ligeiramente assimétrica à direita. A cauda esquerda da distribuição é mais longa, uma vez que existe um pequeno percentual de indivíduos com proficiência extremamente baixa, ao passo que à direita não são identificados indivíduos com nível de proficiência extremamente alto.

O nível de educação financeira baixo, com aproximadamente $22 \%$ dos entrevistados, é formado pelos itens âncoras $6,10,11$ e 13 e as questóes quase âncoras 4 e 8. Indivíduos desse nível são capazes de realizar operações financeiras simples como a divisão de recursos, fazer cálculos básicos com taxas de juros, compreender o conceito e impacto da inflação no custo dos produtos e possuem

\section{Tabela 5}

Intervalos, percentual de casos, itens âncora e quase âncora dos níveis de proficiência em educação financeira.

\begin{tabular}{l|c|c|c|c}
\hline $\begin{array}{l}\text { Nível de } \\
\text { proficiência }\end{array}$ & $\begin{array}{c}\text { Intervalo de } \\
\text { proficiência }\end{array}$ & $\begin{array}{c}\text { Frequência } \\
\text { percentual }\end{array}$ & Itens âncora & $\begin{array}{c}\text { Itens quase } \\
\text { âncoras }\end{array}$ \\
\hline Muito Baixo & $\mathrm{p} \leq-1,5$ & 5,2 & - & - \\
\hline Baixo & $-1,5<\mathrm{p} \leq-0,5$ & 21,89 & $6,10,11$ e 13 & 4 e 8 \\
\hline Médio & $-0,5<\mathrm{p} \leq 0,5$ & 41,12 & 3,9 e 12 & - \\
\hline Alto & $0,5<\mathrm{p} \leq 1,5$ & 31,79 & 7 & - \\
\hline
\end{tabular}


uma noção básica de risco. Tais temáticas são características do que a literatura tem tratado como conhecimento financeiro básico, ou seja, esses indivíduos possuem as habilidades básicas no que se refere à educação financeira (BATEMAN et al., 2012; GERRANS \& HEANEY, 2014)

O nível de educação financeira médio, além de dominar as temáticas do nível baixo, avança na habilidade de resolver as questóes âncoras 3, 9 e 12. Nesse grupo, observa-se que os indivíduos passam a dominar questóes mais complexas como a análise comparativa de juros, conhecem o funcionamento de produtos financeiros básicos como a poupança e possuem noçôes dos custos, riscos e retornos dos produtos financeiros.

Já o nível alto, com $32 \%$ dos entrevistados, tem como questão âncora o item 7 "Quando um investidor distribui seu investimento entre diferentes ativos, o risco de perder dinheiro", indicando claramente que os indivíduos que fazem parte desse grupo são aqueles capazes de entender conceitos mais complexos como o de diversificação de carteiras. O entendimento do conceito de diversificação implica conhecimentos financeiros mais elaborados como risco, retorno e correlação de um conjunto de ativos sendo, portanto, uma temática classificada como mais avançada nos estudos de educação financeira (GERRANS \& HEANEY, 2014; POTRICH; VIEIRA; KIRCH, 2016).

Em seguida, buscou-se avaliar se o nível de proficiência pode estar associado a algumas características do entrevistado (sexo e educação formal) e a educação de seus pais. A Tabela 6 apresenta a distribuição de frequência segundo o nível de proficiência e os resultados do teste $\chi^{2}$.

\section{Figura 3}

Histograma da proficiência em educação financeira.

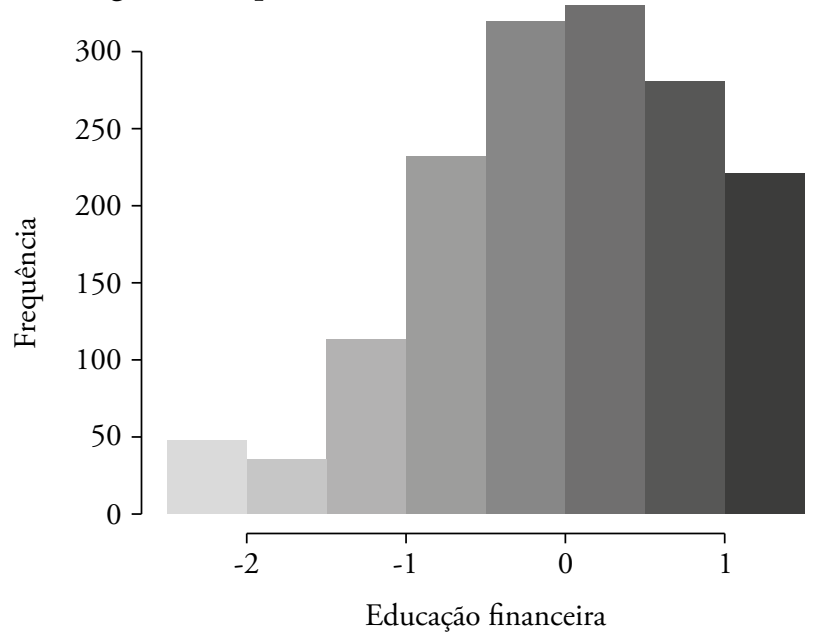




\section{Tabela 6}

Frequência das variáveis sexo, renda familiar, educação do entrevistado do pai e da mãe, segundo o nível de proficiência.

\begin{tabular}{|c|c|c|c|c|c|c|}
\hline \multirow[b]{2}{*}{ Variáveis } & \multirow[b]{2}{*}{ Categorias } & \multicolumn{4}{|c|}{ Nível de Proficiência } & \multirow{2}{*}{$\begin{array}{c}\text { Qui-Quadrado } \\
\text { Valor (sig) }\end{array}$} \\
\hline & & $\begin{array}{l}\text { Muito } \\
\text { baixo }\end{array}$ & Baixo & Médio & Alto & \\
\hline \multirow{2}{*}{ Sexo } & Masculino & $4.8 \%$ & $15.2 \%$ & $38.0 \%$ & $42.0 \%$ & \multirow{2}{*}{$69,52(0,000)$} \\
\hline & Feminino & $5.6 \%$ & $27.3 \%$ & $43.4 \%$ & $23.7 \%$ & \\
\hline \multirow{7}{*}{$\begin{array}{l}\text { Faixa de } \\
\text { renda média } \\
\text { mensal } \\
\text { familiar: }\end{array}$} & Até R\$ 700,00 & $8.9 \%$ & $35.6 \%$ & $44.4 \%$ & $11.1 \%$ & \multirow{7}{*}{$116,98(0,000)$} \\
\hline & $\begin{array}{c}\text { Entre } R \$ 700,01 \\
\text { e R\$ } 1.400,00\end{array}$ & $11.9 \%$ & $28.4 \%$ & $42.0 \%$ & $17.6 \%$ & \\
\hline & $\begin{array}{c}\text { Entre } R \$ 1.400,01 \mathrm{e} \\
\mathrm{R} \$ 2.100,00\end{array}$ & $6.6 \%$ & $28.0 \%$ & $44.4 \%$ & $21.0 \%$ & \\
\hline & $\begin{array}{c}\text { Entre } R \$ 2.100,01 \mathrm{e} \\
\mathrm{R} \$ 3.500,00 \\
\end{array}$ & $5.4 \%$ & $23.9 \%$ & $42.9 \%$ & $27.8 \%$ & \\
\hline & $\begin{array}{c}\text { Entre } R \$ 3.500,01 \mathrm{e} \\
\mathrm{R} \$ 7.000,00\end{array}$ & $2.6 \%$ & $18.1 \%$ & $39.8 \%$ & $39.5 \%$ & \\
\hline & $\begin{array}{l}\text { Entre } R \$ 7.000,01 \mathrm{e} \\
\mathrm{R} \$ 14.000,00\end{array}$ & $2.6 \%$ & $14.4 \%$ & $35.1 \%$ & $47.9 \%$ & \\
\hline & Mais de $\mathrm{R} \$ 14.000,00$ & $2.7 \%$ & $9.5 \%$ & $35.1 \%$ & $52.7 \%$ & \\
\hline \multirow{6}{*}{$\begin{array}{l}\text { Qual o seu } \\
\text { nível de } \\
\text { escolaridade: }\end{array}$} & Ensino fundamental & $11.5 \%$ & $42.7 \%$ & $39.6 \%$ & $6.3 \%$ & \multirow{6}{*}{$75,01(0,000)$} \\
\hline & Ensino médio & $5.6 \%$ & $23.1 \%$ & $41.4 \%$ & $29.9 \%$ & \\
\hline & Ensino superior & $4.4 \%$ & $20.8 \%$ & $40.9 \%$ & $33.9 \%$ & \\
\hline & Curso técnico & $5.9 \%$ & $24.5 \%$ & $43.1 \%$ & $26.5 \%$ & \\
\hline & Especialização ou MBA & $3.4 \%$ & $9.4 \%$ & $40.2 \%$ & $47.0 \%$ & \\
\hline & $\begin{array}{l}\text { Mestrado / Doutorado / } \\
\text { Pós-Doutorado }\end{array}$ & $2.2 \%$ & $15.2 \%$ & $32.6 \%$ & $50.0 \%$ & \\
\hline \multirow{6}{*}{$\begin{array}{l}\text { Qual o maior } \\
\text { nível de } \\
\text { escolaridade } \\
\text { de seu pai: }\end{array}$} & Ensino fundamental & $4.9 \%$ & $23.8 \%$ & $43.6 \%$ & $27.8 \%$ & \multirow{6}{*}{$30,92(0,007)$} \\
\hline & Ensino médio & $6.6 \%$ & $23.2 \%$ & $40.0 \%$ & $30.2 \%$ & \\
\hline & Ensino superior & $3.6 \%$ & $19.0 \%$ & $38.1 \%$ & $39.3 \%$ & \\
\hline & Curso técnico & $4.3 \%$ & $15.7 \%$ & $35.7 \%$ & $44.3 \%$ & \\
\hline & Especialização ou MBA & $5.9 \%$ & $11.8 \%$ & $35.3 \%$ & $47.1 \%$ & \\
\hline & $\begin{array}{l}\text { Mestrado / Doutorado / } \\
\text { Pós-Doutorado }\end{array}$ & $3.0 \%$ & $9.1 \%$ & $39.4 \%$ & $48.5 \%$ & \\
\hline \multirow{6}{*}{$\begin{array}{l}\text { Qual o maior } \\
\text { nível de } \\
\text { escolaridade } \\
\text { de sua mãe: }\end{array}$} & Ensino fundamental & $4.9 \%$ & $24.7 \%$ & $43.1 \%$ & $27.3 \%$ & \multirow{6}{*}{$31,57(0,007)$} \\
\hline & Ensino médio & $7.4 \%$ & $22.2 \%$ & $38.8 \%$ & $31.6 \%$ & \\
\hline & Ensino superior & $3.4 \%$ & $18.2 \%$ & $37.5 \%$ & $40.9 \%$ & \\
\hline & Curso técnico & $5.6 \%$ & $19.7 \%$ & $40.8 \%$ & $33.8 \%$ & \\
\hline & Especialização ou MBA & $1.3 \%$ & $12.0 \%$ & $46.7 \%$ & $40.0 \%$ & \\
\hline & $\begin{array}{l}\text { Mestrado / Doutorado / } \\
\text { Pós-Doutorado }\end{array}$ & $5.0 \%$ & $17.5 \%$ & $42.5 \%$ & $35.0 \%$ & \\
\hline
\end{tabular}


Os níveis de significância do teste $\chi^{2}$ indicam que existem associaçôes entre todas as variáveis analisadas e o nível de proficiência. Quanto ao sexo, observa-se que os percentuais de mulheres nos níveis mais baixos são superiores ao de homens. Por outro lado, observa-se que o percentual dos homens (42\%) que estâo no nível de proficiência alto é muito superior ao de mulheres $(23,7 \%)$. Tais resultados vão ao encontro dos diversos estudos que indicam que homens são mais educados financeiramente do que mulheres (ATKINSON \& MESSY, 2012; SCHERESBERG, 2013; LUSARDI \& WALLACE, 2013; BUCHER-KOENEN et al., 2014; MAHDAVI \& HORTON, 2014; AGARWALLA et al., 2015). De acordo com a OECD (2013b), uma das principais justificativas encontradas para essa disparidade é a maneira como meninos e meninas crescem e são expostos a diferentes oportunidades de aprendizagem e aperfeiçoamento das suas competências financeiras, sendo as meninas protegidas desse processo enquanto os meninos são incentivados a enfrentá-lo.

Quanto à variável renda familiar, observa-se que os percentuais de indivíduos com renda mais baixas são maiores nos níveis de proficiências também mais baixos. Na medida em que se desloca para maiores níveis de renda, observa-se um acréscimo no percentual de indivíduos que atingem o nível alto de proficiência. Tais resultados coincidem com uma ampla literatura que indica uma associação positiva entre o nível de renda e a educação financeira (ATKINSON \& MESSY, 2012; GERRANS \& HEANEY, 2014; SALLEH, 2015; CLARK; LUSARDI; MITCHELL, 2015; GROHMANN; KOUWENBERG; MENKHOFF, 2015).

Para a análise da dependência do nível de educação financeira ao nível de educação formal, avaliou-se tanto a educação do entrevistado como a educação dos seus pais, devido às evidências na literatura de que a educaçáo dos pais influencia a educação financeira dos filhos (BROWN \& TAYLOR, 2016). Os resultados indicam que $54,3 \%$ dos indivíduos que possuem ensino fundamental estão nos níveis de educação financeira baixos e apenas 6,3\% conseguem atingir uma proficiência alta. Por outro lado, dentre aqueles que concluíram o ensino médio há um percentual mais significativo de indivíduos que conseguem atingir a proficiência alta (29,9\%), indicando uma nítida melhora no nível de educação financeira com a conclusão do ensino médio.

Os percentuais para o ensino técnico são muito semelhantes aos do ensino fundamental. Entre os indivíduos que concluíram o ensino superior, observa-se pequena melhora no percentual de alta proficiência, sugerindo não haver ganhos expressivos no nível de proficiência com a conclusão do curso superior em relação ao ensino médio. Já com conclusão de cursos de pós-graduação (MBA, ou mestrado/doutorado), aumenta-se consideravelmente o percentual de indivíduos que alcança níveis altos de proficiência financeira.

A influência tanto do pai quanto da mãe é muito semelhante. No geral, quando os pais possuem maiores níveis de instrução (curso superior ou pós-graduação), observa-se maiores percentuais nos níveis médio e alto, ou seja, filhos de pais com nível graduação ou superior tendem a apresentar maiores proficiências. 
Constata-se, ainda, que mesmo quando os pais têm apenas o ensino fundamental, em torno de $27 \%$ dos entrevistados conseguem alcançar proficiência alta.

Na última etapa de análise, como na amostra original todos os parâmetros de dificuldade foram negativos, optou-se por simular a inserção de dois novos itens com parâmetros de dificuldade positivos, a fim de verificar o impacto da inclusão de novos itens no instrumento proposto.

Os parâmetros de discriminação e dificuldade dessas questóes foram obtidos a partir do estudo de Knoll e Houts (2012), no qual os itens foram calibrados numa escala com média igual a zero e desvio padrão igual a um $(0,1)$. Embora a escala $(0,1)$ gerada por Knoll e Houts (2012) não seja a mesma escala $(0,1)$ gerada nessa análise, foi considerado que esses dois itens também teriam um índice de dificuldade maior se fossem incluídos originalmente na escala proposta. Embora isso seja apenas uma conjectura para fins de simulação, há indícios que corroboram com essa afirmaçáo, pois esses itens apresentam um conteúdo teórico mais avançado em termos de conhecimento financeiro.

Assim, a amostra simulada foi composta pelos 11 itens da amostra original mais os seguintes: item 14 "Quando a taxa de juros aumenta, o que deve acontecer com o preço dos títulos?" ( $\mathrm{a}=0,88 ; \mathrm{b}=1,78)$ e item 15 "Suponha que você deva R \$ 1.000,00 em seu cartão de crédito e pague um pagamento mínimo de $\mathrm{R} \$ 100$ a cada mês. Com taxa de juros de $10 \%$ ao mês, quantos anos levaria para você eliminar a dívida do cartão de crédito?" $(a=1,72 ; b=1,31)$. Portanto, foram simuladas respostas para esses dois itens e reestimadas as proficiências utilizando os mesmos critérios de estimação da amostra original. A Tabela 7 e a Figura 4 apresentam os resultados da simulação dos novos níveis de proficiência com a inserção das novas questóes. Com a inserção dos novos itens no indicador de educação financeira, observa-se uma melhora na simetria da distribuiçáo (Figura 4) e o surgimento de um novo nível de proficiência classificado como muito alto (Tabela 7). Nesse nível de proficiência, além de dominar os conteúdos dos demais níveis, os indivíduos são capazes de aplicar os conhecimentos financeiros na análise de um produto financeiro específico (cartão de crédito). A simulação indica que apenas 2,86\% dos entrevistados atingiriam esse nível.

\section{Considerações finais}

A educação financeira é um dos pilares da cidadania financeira e um instrumento capaz de influenciar diretamente em fatores comportamentais importantes, como a compulsividade nas compras, o uso adequado dos cartóes de crédito e a propensão ao endividamento. Como a própria OECD (2015) argumenta, a educação financeira é um caminho indispensável para que os indivíduos 
alcancem o bem-estar financeiro. A premissa é corroborada por Messy e Monticone (2016), ao afirmarem que a educação financeira é essencial para a proteção e a inclusão financeira dos consumidores.

Nesse contexto, diversos países, entre eles o Brasil, estáo buscando implementar estratégias nacionais para a melhoria do nível de educação financeira da população. Algumas açóes iniciais, como a incorporação da educação financeira na base curricular e a criação da Estratégia Nacional de Educação Financeira, já estáo sendo efetivadas. Entretanto, ainda não se tem, na literatura, um modelo de avaliação da educação financeira consolidado.

Assim, esse trabalho desenvolveu e validou, através da Teoria da Resposta ao Item, um indicador de educação financeira. Os resultados demonstraram que os níveis mais baixos na escala dominam apenas os conhecimentos básicos de

\section{Tabela 7}

Intervalos, percentual de casos, itens âncora e quase âncora dos níveis de proficiência em educação financeira simulados.

\begin{tabular}{l|c|c|c|c}
\hline $\begin{array}{l}\text { Nível de } \\
\text { proficiência }\end{array}$ & $\begin{array}{c}\text { Intervalo de } \\
\text { proficiência }\end{array}$ & $\begin{array}{c}\text { Frequência } \\
\text { percentual }\end{array}$ & Itens âncora & $\begin{array}{c}\text { Itens quase } \\
\text { âncoras }\end{array}$ \\
\hline Muito baixo & $\mathrm{p} \leq-1,5$ & 5,27 & - & - \\
\hline Baixo & $-1,5<\mathrm{p} \leq-0,5$ & 22,08 & $6,10,11 \mathrm{e} 13$ & $4 \mathrm{e} 8$ \\
\hline Médio & $-0,5<\mathrm{p} \leq 0,5$ & 44,1 & 3,9 e 12 & - \\
\hline Alto & $0,5<\mathrm{p} \leq 1,5$ & 25,7 & 7 & - \\
\hline Muito alto & $\mathrm{p}>1,5$ & 2,86 & 15 & - \\
\hline
\end{tabular}

\section{Figura 4}

Histograma da proficiência em educação financeira simulada.

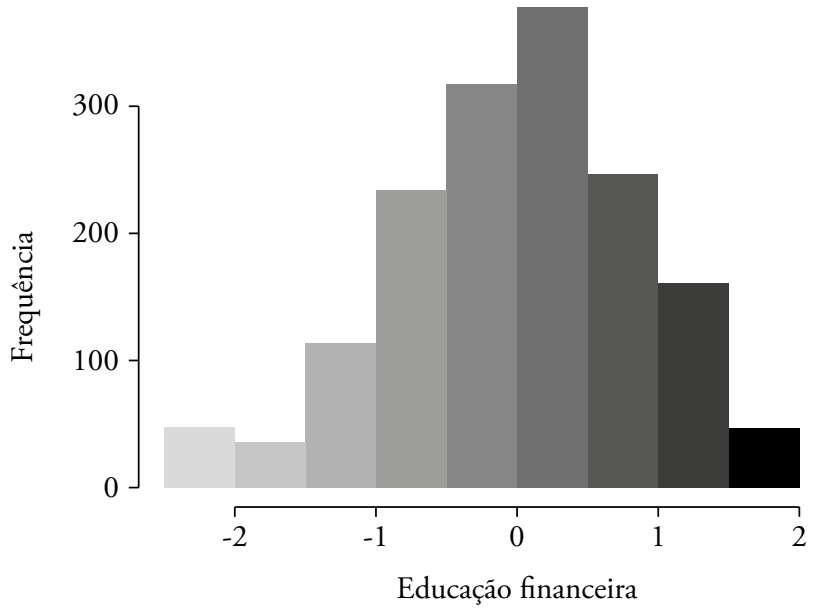


finanças e, na medida em que se avança na escala de educação financeira. Os indivíduos, além de dominar os conhecimentos básicos, passam a dominar itens que representam conhecimentos mais avançados.

A comparação dos níveis de proficiência com o sexo corrobora com os estudos de alfabetização financeira que mostram a menor proficiência do sexo feminino. Os resultados para a educação formal mostraram que os indivíduos com ensino fundamental dificilmente alcançam os níveis maiores de proficiência. No entanto, mostrou que concluir o ensino técnico ou médio aumenta a possibilidade do cidadão atingir níveis mais altos de proficiência.

Em função da dificuldade dos itens originalmente propostos, indicando que instrumento proposto era mais adequado para avaliaçấo de proficiências abaixo da média, optou-se pela proposição de dois novos itens mais difíceis. Os resultados da simulação indicam a adequaçáo dos itens propostos para a composição do indicador de educação financeira e permitiram a construção de uma escala de proficiência com cinco níveis. Assim, os resultados apontam que o instrumento é um indicador adequado para a avaliação da educação financeira.

Entende-se que o indicador de educaçáo financeira pode ser útil tanto para avaliar o nível inicial de conhecimento, visando identificar os temas principais a serem abordados em cursos de educação financeira, quanto para comparação de diferentes grupos sócio demográficos, buscando identificar os grupos prioritários de atendimento nas estratégias nacionais. Também pode ser utilizado em estudos longitudinais para identificar os efeitos da adoçâo de estratégias de educação financeira no nível e proficiência dos indivíduos.

De fato, para que no futuro seja possível uma análise multidimensional dos efeitos das medidas que o Brasil, ou qualquer outro país, adote para melhoria da educação financeira, é indispensável que, entre as diversas dimensóes de análise, seja incluída uma dimensão relativa à proficiência, da qual o indicador de educação financeira pode ser um dos parâmetros. Nesse sentido, é fundamental o papel do ensino formal como uma referência para a construção de um país com mais educação financeira. A ampliação do domínio da matemática sem dúvida é um primeiro passo, mas a incorporaçáo de novas estratégias, possivelmente em um contexto multidisciplinar, é indispensável. Melhorar a educação financeira resultará em cidadãos mais conscientes de suas decisões de consumo, menos propensos à inadimplência e mais capazes de realizar uma adequada gestão financeira familiar. Incluir a educação financeira na agenda política global pode desempenhar um papel importante no empoderamento financeiro dos cidadáos e, como consequência, apresentar influência positiva na estabilidade do sistema financeiro e da economia (BCB, 2017).

Pesquisas futuras podem e devem avançar no sentido de analisar também as dimensóes relativas às atitudes e aos comportamentos financeiros dos indivíduos, 
pois a educação financeira só será efetiva se for capaz de promover comportamentos financeiros mais adequados. Nesse sentido, para alcançar a cidadania financeira um país precisa, além de garantir a proteção ao consumidor de serviços financeiros e a inclusão financeira, promover uma educação financeira de qualidade.

\section{Referências}

AGARWALLA, S. K.; BARUA, S.; JACOB, J.; VARMA, J. R. Financial Literacy among Working Young in Urban India. World Development, v. 67, p. 101-109, 2015. Disponível em: <https://doi.org/10.1016/j.worlddev.2014.10.004 >. Acesso em: $1^{10}$ set. 2018

ANDRADE, D. F.; TAVARES, H. R.; VALLE, R. C. Teoria de resposta ao item: conceitos e aplicaçôes. São Paulo: Associação Brasileira de Estatística, 2000.

ATKINSON, A.; MESSY, F. Measuring financial literacy: results of the OECD / International Network on Financial Education (INFE) pilot study. OECD Publishing, 2012. Disponível em: <http://dx.doi.org/10.1787/5k9csfs90fr4-en>. Acesso em: 2 abr. 2016.

ASSOCIAÇÃO DE EDUCAÇÃO FINANCEIRA DO BRASIL. Programa de Educaçáo Financeira nas Escolas. Brasil: AEF Brasil, 2017. Disponível em: <http://www.aefbrasil. org.br/>. Acesso em: 26 mar. 2017.

BAKER, F. B. The basics of item response theory. 2001. Disponível em: <http://files. eric.ed.gov/fulltext/ED458219.pdf $>$. Acesso em: 15 jun. 2016.

BANCO CENTRAL DO BRASIL (BCB). Série Cidadania Financeira: estudos sobre educação, proteção e inclusão. 5. ed. Brasília: Banco Central do Brasil, 2017. Disponível em: <http://www.bcb.gov.br/nor/relincfin/serie cidadania financeira pesquisa infe br \%200443 2017.pdf >. Acesso em: 6 jun. 2018.

BARCELlOS, S. H.; CARVALHO, L. S.; SMITH, J. P.; YOONG, J. Financial Education Interventions Targeting Immigrants and Children of Immigrants: Results from a Randomized Control Trial. Journal of Consumer Affairs, v. 50, n. 2, p. 263-285, 2016. https://doi.org/10.1111/joca.12097

BATEMAN, H. et al. Financial competence and expectations formation: Evidence from Australia. Economic Record, v. 88, n. 280, p. 39-63, 2012. https://doi.org/10.1111/ j.1475-4932.2011.00766.x

BEATON, A. E.; ALLEN, N. L. Interpreting scales through scale anchoring. Journal of Educational Statistics, v. 17, p. 191-204, 1992. https://doi. org $/ 10.3102 \% 2 \mathrm{~F} 10769986017002191$

BRASIL. Casa Civil. Decreto no 7.397, de 22 de dezembro de 2010. Brasília, 22 dez. 2010. Disponível em: <http://www.planalto.gov.br/ccivil_03/_ato2007-2010/2010/ decreto/d7397.htm>. Acesso em: 30 maio 2018.

BRASIL. Ministério da Educação. Base Nacional Comum Curricular: Educação é a base. Brasília: Ministério da Educação, 2018. Disponível em: $<$ http://basenacionalcomum.mec. 
gov.br/wp-content/uploads/2018/04/BNCC Ensino Medio embaixa site.pdf $>$. Acesso em: 30 maio 2018.

BROWN, S.; TAYLOR, K. Early influences on saving behaviour: Analysis of British panel data. Journal of Banking \& Finance, v. 62, p. 1-14, 2016. https://doi.org/10.1016/j. jbankfin.2015.09.011

BUCHER-KOENEN, T.; LUSARDI, A.; ALESSIE, R.; VAN ROOIJ, M. How Financially Literate are Women? An Overview and New Insights. NBER Working Paper, n. 20793, 2014. Disponível em: <http://www.nber.org/papers/w20793.pdf>. Acesso em: 2 mar. 2017.

CLARK, R.; LUSARDI, A.; MITCHELL, O. S. Employee Financial Literacy and Retirement Plan Behavior: A Case Study. NBER Working Paper, n. 21461, 2015. Disponível em: <http://www.nber.org/papers/w21461>. Acesso em: 21 fev. 2016. https://doi.org/10.3386/w21461

DELAVANDE, A.; ROHWEDDER, S.; WILLIS, R. J. Preparation for Retirement, Financial Literacy and Cognitive Resources. Michigan Retirement Research Center, 2008.

FERNANDES, D.; LYNCH JR., J. G.; NETEMEYER, R. G. Financial Literacy, Financial Education, and Downstream Financial Behaviors. Management Science, v. 60, n. 8, p. 1861-1883, 2014. https://doi.org/10.1287/mnsc.2013.1849

GERARDI, K.; GOETTE, L.; MEIER, S. Financial Literacy and Subprime Mortgage Delinquency: Evidence from a Survey Matched to Administrative Data. Federal Reserve Bank of Atlanta Working Paper, 2010.

GERRANS, P.; HEANEY, R. A. The Role of Undergraduate Personal Finance Education in Financial Literacy, Financial Attitudes and Financial Behaviours. Social Science Research Network, 2014. Disponível em: <http://dx.doi.org/10.2139/ssrn.25373 44>. Acesso em: 29 fev. 2016.

GROHMANN, A.; KOUWENBERG, R.; MENKHOFF, L. Childhood roots of financial literacy. Journal of Economic Psychology, v. 51, p. 114-133, 2015. https://doi. org/10.1016/j.joep.2015.09.002

HUSTON, S. J. Measuring Financial Literacy. The Journal of Consumer Affairs, v. 44, n. 2, 2010. https://doi.org/10.1111/j.1745-6606.2010.01170.x

INSTITUTO BRASILEIRO DE GEOGRAFIA E ESTATÍSTICA (IBGE). Estatísticas de gênero: uma análise dos resultados do censo demográfico 2010. Rio de Janeiro: IBGE, 2010. Disponível em: <www.ibge.gov.br/apps/snig/v1/>. Acesso em: 21 jan. 2017.

INSTITUTO PAULO MONTENEGRO (IPM). Indicador de Alfabetismo Funcional (INAF): Estudo especial sobre alfabetismo e mundo do trabalho. São Paulo: Instituto Paulo Montenegro, 2016. Disponível em: <http://acaoeducativa.org.br/wp-content/ uploads/2016/09/INAFEstudosEspeciais_2016_Letramento_e_Mundo_do_Trabalho. pdf>. Acesso em: 6 jun. 2018. 
JUNQUEIRA, R. D.; MARTINS, D. A.; LACERDA, C. B. F. Política de Acessibilidade e Exame Nacional do Ensino Médio (ENEM). Educação \& Sociedade, v. 38, n. 139, p. 453-471, 2017.

KLAPPER, L.; LUSARDI, A.; PANOS, G. A. Financial literacy and its consequences: Evidence from Russia during the financial crisis. Journal of Banking \& Finance, v. 37, p. 3904-3923, 2013. https://doi.org/10.1016/j.jbankfin.2013.07.014

KNOLL, M. A. Z.; HOUTS, C. R. The financial knowledge scale: an application of item response theory to the assessment of financial literacy. The Journal of Consumer Affairs, v. 46, n. 3, p. 381-410, 2012. https://doi.org/10.1111/j.1745-6606.2012.01241.x

LUSARDI,A. Financialliteracy: Dopeopleknow theABCsoffinance? Public Understanding of Science, v. 24, n. 3, p. 260-271, 2015. https://doi.org/10.1177\%2F0963662514564516

LUSARDI, A.; MITCHELL, O. S. Financial literacy and retirement planning in the United States. Journal of Pension Economics and Finance, v. 10, n. 4, p. 509-525, 2011. https://doi.org/10.3386/w17108

LUSARDI, A.; MITCHELL, O. S. The Economic Importance of Financial Literacy: Theory and Evidence. Journal of Economic Literature, v. 52, n. 1, p. 5-44, 2014. https:// doi.org/10.3386/w18952

LUSARDI, A.; WALLACE, D. Financial Literacy and Quantitative Reasoning in the High School and College Classroom. Numeracy, v. 6, n. 2, 2013. http://dx.doi. org/10.5038/1936-4660.6.2.1

MAHDAVI, M.; HORTON, N. J. Financial Knowledge among Educated Women: Room for Improvement. Journal of Consumer Affairs, v. 48, n. 2, p. 403-417, 2014. https://doi.org/10.1111/joca.12032

MESSY, F.; MONTICONE, C. Financial Education Policies in Asia and the Pacific. OECD Working Papers on Finance, Insurance and Private Pensions, Paris, n. 40, 2016. Disponível em: <http://dx.doi.org/10.1787/5jm5b32v5vvc-en>. Acesso em: 23 fev. 2016.

NATIONAL FINANCIAL CAPABILITY STUDY (NFCS). Financial Capability in the United States: Report of Findings from the 2012 National Financial Capability Study. Estados Unidos: Financial Industry Regulatory Authority (FINRA)/Investor Education Foundation, 2013.

OPLETALOVÁ, A. Financial education and financial literacy in the Czech education system. Procedia - Social and Behavioral Sciences, v. 171, n. 16, p. 1176-1184, 2015. https://doi.org/10.1016/j.sbspro.2015.01.229

ORGANISATION FOR ECONOMIC CO-OPERATION AND DEVELOPMENT (OECD). Financial literacy and inclusion: Results of OECD/INFE survey across countries and by gender. OECD Publishing, 2013a. Disponível em: <http://www. oecd.org/daf/fin/financialeducation/TrustFund2013 OECD INFE Fin Lit and Incl SurveyResults by Country and Gender.pdf>. Acesso em: 15 abr. 2016.

ORGANISATION FOR ECONOMIC CO-OPERATION AND DEVELOPMENT (OECD). PISA 2015 Results in Focus. OECD Publishing, 2018. Disponível em: <http://www.oecd.org/pisa/pisa-2015-results-in-focus.pdf $>$. Acesso em: 30 maio 2018. 
ORGANISATION FOR ECONOMIC CO-OPERATION AND DEVELOPMENT (OECD). Women and Financial Education: Evidence, Policy Responses and Guidance. OECD Publishing, 2013b. Disponível em:<http://dx.doi.org/10.1787/9789264202733-en>. Acesso em: 25 maio 2018.

ORGANISATION FOR ECONOMIC CO-OPERATION AND DEVELOPMENT (OECD). 2015 OECD/INFE Toolkit for Measuring Financial Literacy and Financial Inclusion. OECD Publishing, 2015. Disponível em: <http://www.oecd.org/daf/fin/ financial-education/2015 OECD INFE Toolkit Measuring Financial Literacy.pdf $>$. Acesso em: 24 fev. 2016.

PARTCHEV, I. Package irtoys: simple interface to the estimation and plotting of IRT models. CRAN R Project, 2016. Disponível em: <http://cran.r-project.org/web/packages/ irtoys/irtoys.pdf >. Acesso em: 24 maio 2017.

POTRICH, A. C. P.; VIEIRA, K. M.; KIRCH, G. Você é Alfabetizado Financeiramente? Descubra no Termômetro de Alfabetização Financeira. Revista Base (Administraçáo e Contabilidade) da Unisinos, v. 13, n. 2, p. 153-170, 2016.

R CORE TEAM. The R Project for statistical computing. Viena: R Foundation for Statistical Computing, 2017. Disponível em: <https:/www.R-project.org/>. Acesso em: 24 maio 2017.

RECKASE, M. D. Unifactor latent trait models applied to multifactor tests: Results and implications. Journal of Educational Statistics, v. 4, p. 207-230, 1979. https://doi. org/10.2307/1164671

SALLEH, A. M. H. A. P. M. A comparison on financial literacy between welfare recipients and non-welfare recipients in Brunei. International Journal of Social Economics, v. 42, n. 7, p. 598-613, 2015. https://doi.org/10.1108/IJSE-09-2013-0210

SCHERESBERG, C. B. Financial literacy and financial behavior among young adults: Evidence and implications. Numeracy, v. 6, n. 2, 2013. http://dx.doi.org/10.5038/1936$\underline{4660.6 .2 .5}$

SCHMEISER, M. D.; SELIGMAN, J. S. Using the Right Yardstick: Assessing Financial Literacy Measures by Way of Financial Well-Being. The Journal of Consumer Affairs, v. 47, n. 2, p. 243-262, 2013. https://doi.org/10.1111/joca.12010

VAN ROOIJ, M. C. J; LUSARDI, A.; ALESSIE, R. J. M. Financial Literacy and retirement planning in the Netherlands. Journal of Economic Psychology, v. 32, n. 4, p. 593-608, 2011. https://doi.org/10.1016/j.joep.2011.02.004

Recebido em 11 de julho de 2017.

Aceito em 21 de agosto de 2018.

(C) 2019 Centro de Estudos Educação e Sociedade - CEDES Este é um artigo de acesso aberto distribuído nos termos de licença Creative Commons. 